\title{
Chapitre IV - Essais de typologie des compagnies de
} CFIL et de TVM

\section{Maurice Wolkowitsch}

\section{OpenEdition}

\section{Journals}

Édition électronique

URL : https://journals.openedition.org/rhcf/1312

DOI : 10.4000/rhcf.1312

\section{Éditeur}

Rails \& histoire

\section{Édition imprimée}

Date de publication : 10 février 2004

Pagination : $90-152$

ISBN : 0996-9403

ISSN : 0996-9403

\section{Référence électronique}

Maurice Wolkowitsch, "Chapitre IV - Essais de typologie des compagnies de CFIL et de TVM », Revue d'histoire des chemins de fer [En ligne], 30 | 2004, mis en ligne le 26 août 2012, consulté le 22 avril 2022. URL : http://journals.openedition.org/rhcf/1312 ; DOI : https://doi.org/10.4000/rhcf.1312 


\section{Chapitre IV}

\section{Essais de typologie des compagnies de CFIL et de TVM}

es compagnies d'intérêt général règnent sur un réseau où la de tutelle ; leurs dirigeants compétents sortent des mêmes grandes écoles, Polytechnique, les Mines, les Ponts ; leurs conseils d'administration sont composés des représentants des mêmes milieux financiers, industriels et politiques. La multiplicité des compagnies secondaires exclut qu'elles connaissent une même situation. À travers leur diversité, il convient d'en proposer une classification. Quels critères retenir ?

Le statut juridique est à écarter, de nombreuses compagnies exploitant des lignes concédées sous les divers régimes proposés. Les entrepreneurs ne s'embarrassent pas de ces subtilités pour donner un nom à leur compagnie : la Compagnie des tramways de la Sarthe relève du régime des CFIL 1880 ; la Compagnie des chemins de fer du Périgord de celui des TVM.

Une première approche est simple : elle vise à reconnaître l'importance des entreprises d'après le kilométrage exploité à un moment donné pour autoriser des comparaisons. Cette approche objective permet d'évoquer le territoire desservi et le degré de connexité du réseau constitué. Enfin, la part prise par chaque catégorie d'entreprises dans l'ensemble du réseau donne une idée de la structure de ce secteur d'activité.

Une seconde approche est indispensable, recoupant partiellement la première. Elle fait intervenir les problèmes de financement, de gestion, d'organisation, le rôle des hommes. Le domaine est plus complexe à explorer puisque tous ces éléments devraient être connus pour toutes les entreprises, ce qui n'est évidemment pas le cas. Leur nombre exclut cette ambition, sans parler de la documentation disparue; nous nous appuierons donc sur des exemples.

1- P. Dancoisne "Théorie des graphes et construction du réseau ferré français », thèse pour le doctorat, université de Paris I - Panthéon-Sorbonne, 1984, 280 p. 


\section{Typologie d'après le kilométrage exploité}

\section{- Compagnies exploitant de une à trois lignes et rarement plus de $\mathbf{5 0} \mathbf{~ k m}$ (annexe 1)}

Beaucoup de compagnies ont reçu ce type de concession ; aucun projet d'extension n'est prévu; le cas existe pour les TVM, comme pour les CFIL. Une typologie de lignes peut être suggérée : on distingue des lignes de desserte urbaine ou périurbaine avec une prédilection pour les liaisons entre gare et centre ville, des lignes de desserte de zones rurales, enfin des relations à vocation touristique caractérisée. L'emploi de techniques particulières (funiculaire, crémaillère) s'impose quelquefois. On soulignera que la longueur des lignes concernées va de quelques centaines de mètres à quelques dizaines de kilomètres (tabl. 4). Des personnes physiques se sont intéressées à l'origine à ce type d'exploitation; elles ont connu des difficultés à passer de la concession à la construction.

Tableau 4. Exemples de sociétés exploitant une relation unique CFIL ou TVM voyageurs

\begin{tabular}{|l|l|c|}
\hline \multicolumn{3}{|c|}{ Lignes urbaines ou périurbaines } \\
\hline Régime & \multicolumn{1}{|c|}{ Compagnie } & km \\
\hline CFIL 1880 & Chemin de fer d'Aigues-Vives-Bourg à Aigues-Vives-PLM & 2 \\
\hline CFIL 1880 & Société du Chemin de fer de Laon-gare à Laon-ville & 1 \\
\hline CFIL 1880 & Ville de Langres : gare-ville & 1,5 \\
\hline TVM & Société de Tramw ay de Cassel : gare-ville & 4 \\
\hline TVM & Société de Tramw ay Electrique de Rodez : gare-ville & 2 \\
\hline \multicolumn{2}{|c|}{ Lignes de desserte rurale } & Com pagnie \\
\hline Régime & \multicolumn{2}{|c|}{ km } \\
\hline CFIL 1865 & Compagnie du Chemin de Fer de Mamers à Saint-Calais & 77 \\
\hline CFIL 1880 & Compagnie du CFIL d'Andelot PLMà Levier & 27 \\
\hline TVM & Tramw ay de Pithiviers à Toury & 31 \\
\hline TVM & $\begin{array}{l}\text { Compagnie de Chemin de Fer des Vosges : Remiremont à } \\
\text { Gérardmer }\end{array}$ & 27 \\
\hline TVM & $\begin{array}{l}\text { Compagnie de Chemin de Fer à Voie Etroite de Tramw ay à } \\
\text { Vapeur du Tarn : Lavaur à Laboutarié }\end{array}$ & 34 \\
\hline \multicolumn{4}{|c|}{ Lignes à vocation touristique } \\
\hline Régime & & km pagnie \\
\hline CFIL 1880 & Compagnie de Chemin de Fer de Berck-plage à Paris-plage & 16 \\
\hline CFIL 1880 & Chemin de fer de La Turbie : Monte-Carlo à La Turbie & 3 \\
\hline CFIL 1880 & Société du Chemin de Fer de Chamonix au Montenvers & 5 \\
\hline TVM & Société de Chemin de fer du Salève & 9 \\
\hline
\end{tabular}


. Compagnies exploitant un réseau départemental (annexe 2)

Ces compagnies disposent de 100 à $400 \mathrm{~km}$; certaines desservent par prolongements des départements limitrophes, assurant des liaisons ignorées par le réseau d'intérêt général. Leur réseau a été conçu souvent avec une réelle cohérence et avec la volonté d'assurer une bonne couverture du territoire, même si la réalisation a été étalée dans le temps comme l'attestent les concessions données sous divers régimes juridiques. Ces compagnies sont nombreuses ; des exemples peuvent signaler leurs caractéristiques (tabl. 5).

Tableau 5. Exemples de compagnies exploitant un réseau à base départementale

\begin{tabular}{|c|c|c|c|}
\hline Régime & Compagnie & $\mathrm{Km}$ & Total km \\
\hline CFIL 1865 & \multirow{2}{*}{ CFIL de l'Hérault (a) } & 177 & \\
\hline CFIL 1880 & & 195 & 372 \\
\hline CFIL 1880 & CFIL de l'Anjou (a) & & 316 \\
\hline CFIL 1880 & $\begin{array}{l}\text { Société des chemins de fer départementaux à } \\
\text { voie étroite des Ardennes }\end{array}$ & & 329 \\
\hline CFIL 1880 & Compagnie des chemins de fer du Tarn & & 166 \\
\hline CFIL 1880 & Compagnie du CFIL des Côtes-du-Nord & & 210 \\
\hline CFIL 1880 & \multirow{2}{*}{$\begin{array}{l}\text { Compagnie des tramw ays à vapeur du } \\
\text { département de l'Aude (a) }\end{array}$} & 19 & \\
\hline TVM & & 317 & 336 \\
\hline TVM & $\begin{array}{l}\text { Compagnie des tramw ays à vapeur d'llle-et- } \\
\text { Vilaine (a) }\end{array}$ & & 386 \\
\hline TVM & Société des chemins de fer du Calvados & & 224 \\
\hline TVM & Société des chemins de fer de l'Ardèche & & 141 \\
\hline
\end{tabular}

(a) Réseau intéressant un département voisin.

\section{$>$ Les principales compagnies et les compagnies à réseaux géographiquement dispersés (tabl. 6)}

Cette catégorie rassemble des entreprises différentes par le kilométrage exploité, mais offrant des traits communs : utilisation de plusieurs écartements, présence dans trois départements, ou plus, discontinuité spatiale du réseau, exploitation de concessions sous divers régimes juridiques, l'association TVM-CFIL 1880 étant la plus fréquente sans exclure d'autres cas de figures. Des exceptions existent pour chaque donnée. Les principales entreprises méritent une analyse particulière. L'analyse de l'évolution de leur réseau presque année par année est riche d'enseignements ; les lignes d'intérêt local et d'intérêt général s'y côtoient ; l'histoire des unes ne saurait être séparée de celle des autres. 


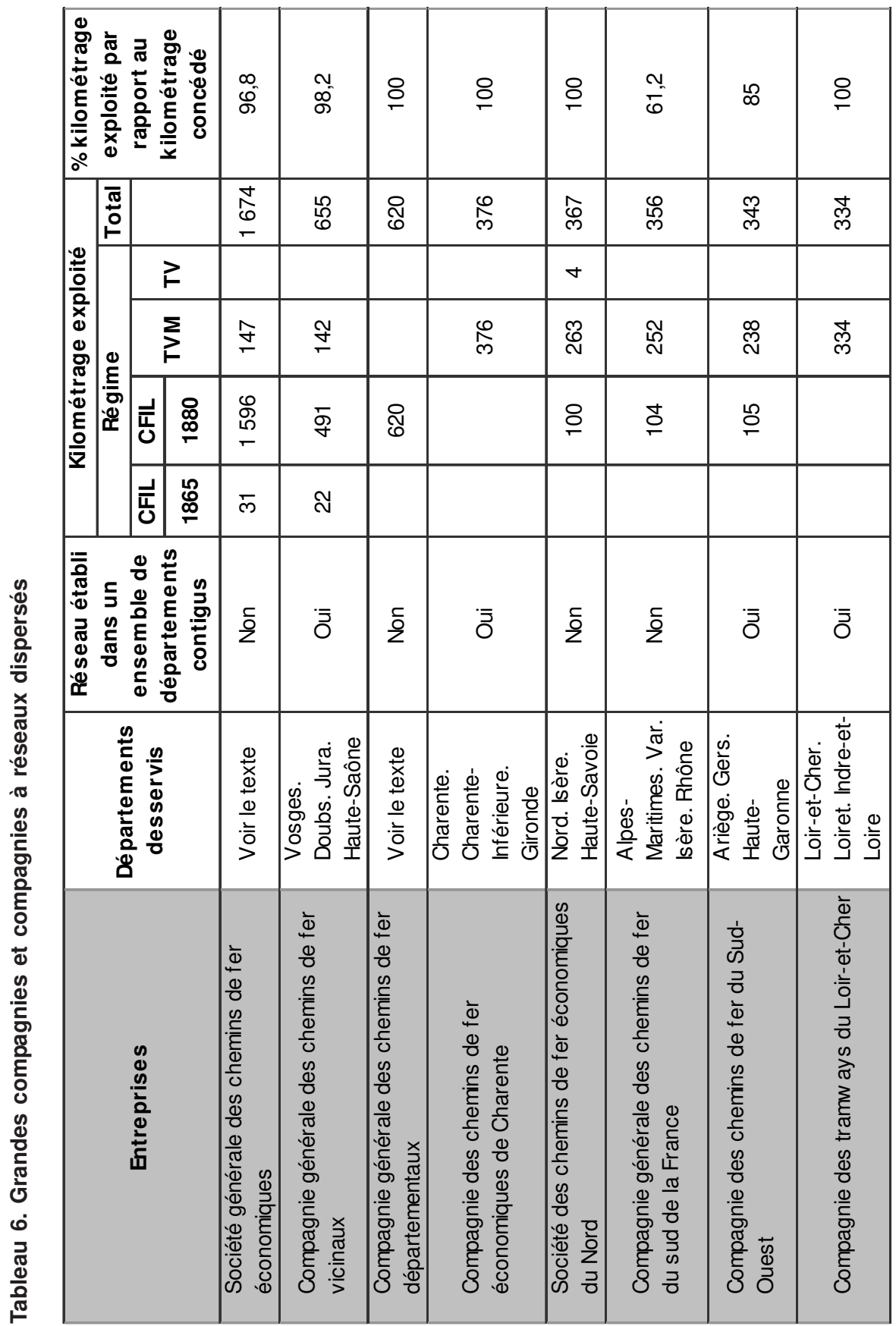




\begin{tabular}{|c|c|c|c|c|c|c|c|c|c|c|c|}
\hline \multicolumn{3}{|c|}{ 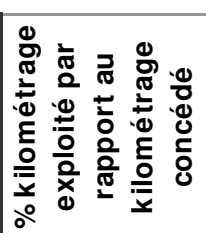 } & 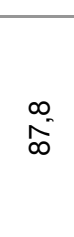 & $\approx$ & 告 & 음 & $\stackrel{\infty}{\wedge}$ & 8 & $\stackrel{\circ}{\circ}$ & $\stackrel{\mathscr{R}}{1}$ & \multirow{2}{*}{ 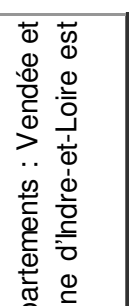 } \\
\hline & \begin{tabular}{|l|l|} 
क्ष \\
\end{tabular} & & 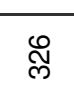 & 岕 & $\stackrel{\mathscr{N}}{\sim}$ & $\stackrel{\mathscr{N}}{N}$ & $\stackrel{N}{N}$ & g & $\stackrel{\mathscr{m}}{\stackrel{1}{2}}$ & $\stackrel{\infty}{\stackrel{\infty}{\circ}}$ & \\
\hline \multirow{4}{*}{ 这 } & & $\vec{z}$ & & & & $\sigma$ & $\stackrel{\substack{\infty \\
上}}{\perp}$ & & & & 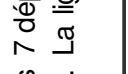 \\
\hline & & $\sum_{i}^{\Sigma}$ & $\stackrel{\infty}{\circ}$ & $\bar{N}$ & & $\stackrel{\mathbb{N}}{\mathbb{N}}$ & $\stackrel{m}{=}$ & $\stackrel{+}{+}$ & $\stackrel{\mathscr{m}}{\underline{m}}$ & $\stackrel{\mathrm{N}}{ }$ & 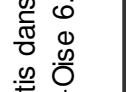 \\
\hline & 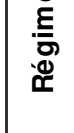 & \begin{tabular}{|l|l|l|}
$\vec{t}$ & $\stackrel{\mathscr{D}}{\mathrm{U}}$ \\
\end{tabular} & 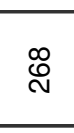 & F & 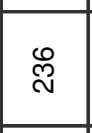 & & $\stackrel{\leftrightarrow}{\infty}$ & $\stackrel{\mathscr{I}}{\stackrel{2}{*}}$ & & R & 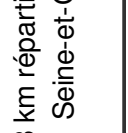 \\
\hline & & 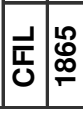 & & & & & - & & & & \\
\hline \multicolumn{3}{|c|}{ 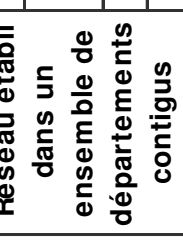 } & 亏亏 & о亏 & $\overline{\bar{O}}$ & $\overline{\bar{O}}$ & $\overline{\bar{O}}$ & $\overline{\bar{O}}$ & $\overline{\bar{O}}$ & '̄ & 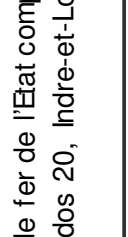 \\
\hline \multicolumn{3}{|c|}{ 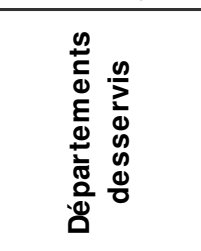 } & 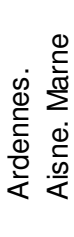 & ฮ & 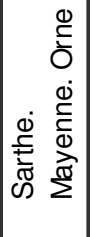 & 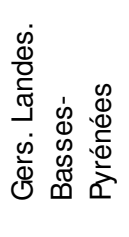 & 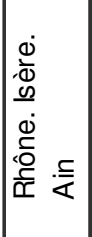 & 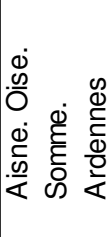 & 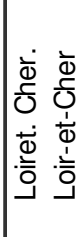 & 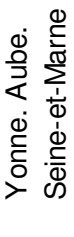 & 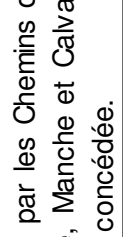 \\
\hline \multicolumn{3}{|c|}{ 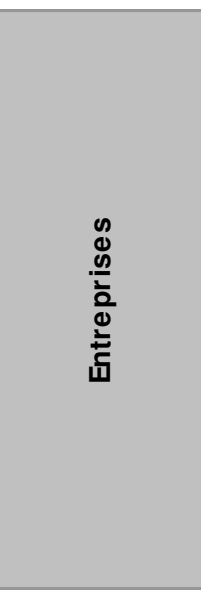 } & 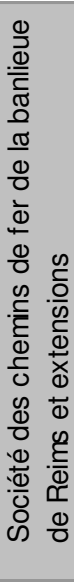 & 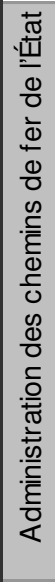 & 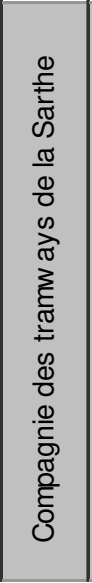 & 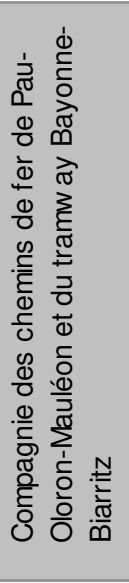 & 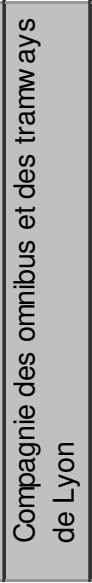 & 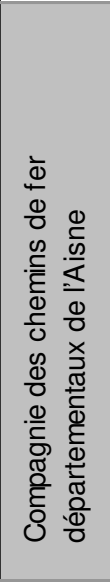 & 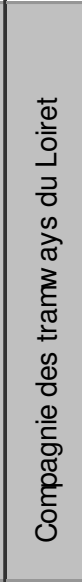 & 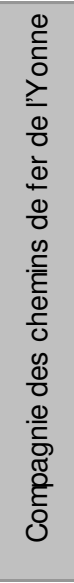 & 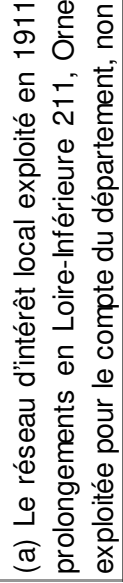 \\
\hline
\end{tabular}




\section{$>$ La Compagnie des chemins de fer départementaux}

\section{Première période : 1882 - 1915}

La Compagnie des chemins de fer départementaux exploite en $1911620 \mathrm{~km}$ de lignes d'intérêt local et $749 \mathrm{~km}$ de lignes d'intérêt général (fig. 3).

Les premières conventions de lignes d'intérêt local sont signées en Indre-et-Loire et en Manche ${ }^{2}$ en 1882 ; les mises en service ont lieu respectivement en 1885 et 1886. Les conventions passées en 1884 dans l'Yonne et la Seine-et-Marne débouchent sur des ouvertures en 1888 et 1889 ; soulignons la rapidité de l'exécution des travaux. Le réseau compte $447 \mathrm{~km}$ en 1889 dont 196 en Indre-et-Loire ; ce département dispose de $240 \mathrm{~km}$ en 1911 ; les CFD exploitent un réseau de plus de $100 \mathrm{~km}$ en Seine-et-Marne; dans les autres départements où la compagnie est présente, on a en général des lignes courtes et isolées (Charente, Saône-et-Loire, Yonne, Charente-Inférieure). Le réseau s'enrichit de quelques liaisons entre 1893 et 1907, année de la dernière ouverture de deux lignes d'intérêt local ${ }^{3}$.

Le réseau d'intérêt général équipe deux régions montagneuses aux ressources faibles. L'État accorde des concessions d'intérêt général pour être partie prenante dans les projets et favoriser le désenclavement. Le réseau corse s'étend rapidement ${ }^{4}$ : les conventions de 1883 conduisent entre 1888 et 1890 à l'ouverture de $267 \mathrm{~km}$; plus de 300 sont en service en 1894. Entre 1890 et 1909, Ardèche, Haute-Loire et Lozère sont équipés d'un réseau de $212 \mathrm{~km}$; le PLM a-t-il été sollicité pour construire ces lignes imbriquées dans les siennes? Est-ce après son refus que les CFD ont été chargés de l'opération ? Seule certitude, malgré la concession d'intérêt général, l'État a cherché la construction et la gestion à l'économie avec le choix de la voie métrique et d'une compagnie expérimentée dans l'exploitation des lignes secondaires. Si on comprend les efforts consentis pour des régions en difficulté, les concessions de lignes d'intérêt général accordées en Charente-Inférieure, plus de $200 \mathrm{~km}$, surprennent ; quels mobiles ont pu pousser à ces décisions ? Ce département est loin d'être dans la situation de la Corse ou de la Haute-Loire. C'est en CharenteInférieure que la compagnie ouvre en 1915 sa dernière ligne sur le continent, entre Saintes et Burie.

2- En Indre-et-Loire : Neuillé-Pont-Pierre à Château-Renault $(39 \mathrm{~km})$ et à Port-Boulet $(64 \mathrm{~km})$; en Manche: Valognes à Barfleur $(35 \mathrm{~km})$ et Montebourg à Saint-Martind'Audouville $(9 \mathrm{~km})$.

3- En Indre-et-Loire : Montrésor avec prolongement dans l'Indre jusqu’à Écueillé $(20 \mathrm{~km})$, Fondettes à Rillé $(9 \mathrm{~km})$.

4- P. Planeix, «Idées politiques et chemin de fer : le cas de la Corse », Actes du colloque de Lyon, et Riffaud, «Les chemins de fer corses », Rails, $\mathrm{n}^{\circ}$ 40, juin 2000, p. 1-8. 


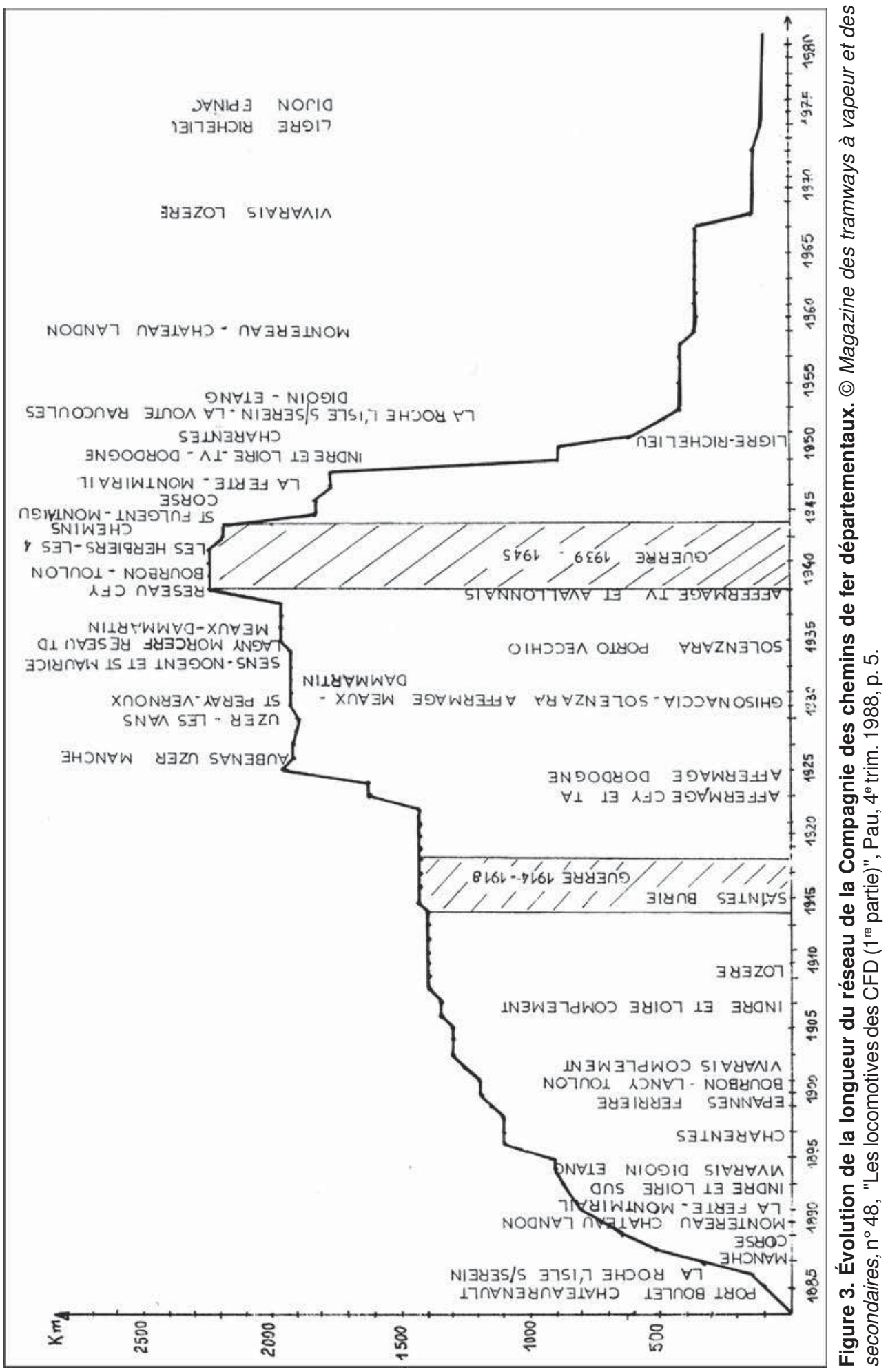




\section{Deuxième période : 1920-1973}

L'évolution du réseau résulte de plusieurs types d'actions, les unes visant à allonger le réseau, une autre à le réduire. Il n'est pas possible d'ignorer le sort du réseau d'intérêt général, d'autant que tout l'apparente dans son exploitation et sa fonction de proximité aux chemins de fer secondaires.

L'allongement du réseau est le fruit de deux politiques. Deux concessions de 1909 portant sur $65 \mathrm{~km}$ sont exécutées en établissant les liaisons de Solenzara à Ghisonaccia (1930) et à Porto-Vecchio (1935); ces lignes sont les dernières construites par les CFD; le réseau corse atteint $337 \mathrm{~km}$. Le développement est surtout dû à l'affermage par les CFD des réseaux d'entreprises de VFIL qui cessent d'en assurer l'exploitation : plus de $1200 \mathrm{~km}$ de lignes sont ainsi pris en charge dans le cadre de conventions signées entre 1922 et 1950 ; les principales opérations ont lieu dans l'Yonne (193 km en 1923), en Dordogne (307 km en 1927), en Vendée (366 km en 1938). Des traités avec la SNCF afferment aux CFD en 1939 les lignes de Maison-Dieu à Dracy-Saint-Loup, et de Dijon à Épinac, en 1947 la ligne de Tours à Esvres, en 1950 les lignes de Ligré-Rivière à Tours et à Richelieu, en tout $228 \mathrm{~km}$ à écartement normal à $93 \%$ et sous le régime de concession d'intérêt général. 80 \% du réseau affermé est à voie métrique et formé de lignes de VFIL.

Parallèlement à cette politique d'extension, les CFD amorcent une politique de réduction du réseau ; les lignes concédées et les lignes affermées sont également visées ; certaines sont maintenues en service par d'autres entrepreneurs. Le mouvement, timide jusqu'en 1938, prend son ampleur avec la renaissance de la concurrence automobile en 1949.

La ligne Aubenas-Uzès est la première touchée, en 1925, suivie en 1926 de $45 \mathrm{~km}$ rachetés par le département de la Manche et confiés à la Compagnie des chemins de fer normands. Le mouvement est lent, les CFD délaissent un peu plus de $200 \mathrm{~km}$ en 12 ans. L’année 1939 marque un tournant avec la fermeture de $228 \mathrm{~km}$ de lignes affermées dans l'Yonne, certaines étant reprises par les Chemins de fer du Gâtinais (Sens à Égreville). Cette opération d'envergure est la seule avant la guerre, qui apparait comme une parenthèse dans l'évolution du réseau, sauf en Corse.

L'île n'est occupée que dix mois (novembre 1942 - septembre 1943), cela suffit aux troupes allemandes pour faire subir d'importantes destructions au réseau, notamment à la ligne orientale. Les CFD abandonnent le réseau confié en régie à l'administration des Ponts et Chaussées en 1945 ; le réseau reconstruit partiellement restera vingt ans sous ce statut. Il compte aujourd'hui $231 \mathrm{~km}$; il a perdu le tiers de sa longueur. 
Si, en 1947 et 1948, 129 km de lignes en Vendée et en Seine-etMarne sont fermées, 1949 se traduit par une chute brutale du kilométrage exploité : $826 \mathrm{~km}$ sont concernés dont $70 \%$ de lignes affermées en Dordogne et en Vendée, le réseau concédé d'Indre-et-Loire constitue les $30 \%$ restant. La compagnie abandonne ainsi trois départements. En 1951 vient le tour des réseaux charentais $(289 \mathrm{~km})$, en 1968 celui des réseaux de l'Ardèche et de la Lozère $(227 \mathrm{~km})$.

Les CFD ont exploité longtemps leurs lignes concédées : $40 \%$ des lignes pendant plus de 60 ans (77 ans pour les lignes d'intérêt général Tournon à Lamastre et Le Cheylard à La Voulte-sur-Rhône, 71 ans pour la ligne d'intérêt local de Montereau à Souppes); seulement $17 \%$ pendant moins de 50 ans (32 ans pour la ligne d'intérêt local de Mortcerf à Villeneuve-le-Comte, 36 ans pour la ligne d'intérêt général, de Saintes à Burie). Le régime d'exploitation, intérêt local ou intérêt général n'est pas un facteur de longévité, comme les exemples ci-dessus le montrent.

L'exploitation de lignes affermées par la compagnie a une vie brève sous son contrôle : 21 ans pour les lignes de Dordogne, 11 à 16 pour celles de l'Yonne, 9 à 10 pour celles de Vendée, 5 et 6 pour deux lignes ardéchoises et même 21 mois entre Tours et Esvres, trois entre La-Roche-sur-Yon et Legé. La même année 1939, les CFD condamnaient leur réseau de l'Yonne et affermaient celui de Vendée.

Le réseau concédé concerne 11 départements, le réseau affermé huit; l'affermage est surtout intervenu dans des départements où la compagnie était déjà présente. Seuls cinq départements ont des lignes exploitées sous des régimes différents (tabl. 7). En tout, les CFD ont opéré dans 14 départements; si certains d'entre eux sont limitrophes, cela ne se traduit pas obligatoirement dans la continuité des lignes (Lozère), d'autres sont totalement isolés (Indre-et-Loire, Manche, évidemment Corse). Cette grande société exploite donc un réseau géographiquement dispersé.

L'ouverture de lignes concédées, la prise en charge de lignes affermées, puis les fermetures des unes et des autres entraînent des variations fréquentes du kilométrage exploité : le réseau de l'Yonne passe de 75 à $268 \mathrm{~km}$ pendant 16 ans (1923-1939), celui de l'Ardèche de 178 à $259 \mathrm{~km}$ pendant 6 ans (1923-1929). L'évolution du kilométrage exploité par les CFD dans deux départements montre des variations qui devaient poser de sérieux problèmes de gestion (tabl. 8). 
Tableau 7. Constitution du réseau des CFD

\begin{tabular}{|c|c|c|c|c|c|c|c|c|c|}
\hline & \multicolumn{2}{|c|}{$\begin{array}{l}\text { Réseau } \\
\text { concédé }\end{array}$} & \multicolumn{2}{|c|}{$\begin{array}{l}\text { Réseau } \\
\text { affermé }\end{array}$} & & \multicolumn{2}{|c|}{$\begin{array}{l}\text { Réseau } \\
\text { concé dé }\end{array}$} & \multicolumn{2}{|c|}{$\begin{array}{l}\text { Réseau } \\
\text { affermé }\end{array}$} \\
\hline & i. $g$. & i. I. & i. g. & i. I. & & i. g. & i. I. & i. g. & i. I. \\
\hline Ardèche & $x$ & & & $x$ & Indre-et-Loire & & $x$ & $x$ & $x$ \\
\hline Charente & & $x$ & & & Lozère & $x$ & & & \\
\hline $\begin{array}{l}\text { Charente- } \\
\text { Inférieure }\end{array}$ & $x$ & $x$ & & & Manche & & $x$ & & \\
\hline Corse & $x$ & & & & Saône-et-Loire & & $x$ & $x$ & \\
\hline Côte-d'Or & & & $x$ & & Seine-et-Marne & & $x$ & $x$ & \\
\hline Dordogne & & & & $x$ & Vendée & & & & $x$ \\
\hline Haute-Loire & $x$ & & & & Yonne & & $x$ & & $x$ \\
\hline
\end{tabular}

Tableau 8. Évolution kilométrique des réseaux des CFD en Indre-et-Loire et Seine-et-Marne

\begin{tabular}{|c|c|c|c|}
\hline \multicolumn{2}{|c|}{ Seine-et-Marne } & \multicolumn{2}{|c|}{ Indre-et-Loire } \\
\hline Années & $\mathrm{Km}$ & Années & $\mathrm{Km}$ \\
\hline $1888-1989$ & 45 & $1885-1889$ & 103 \\
\hline $1889-1900$ & 95 & 1889-1907 & 196 \\
\hline $1900-1902$ & 107 & 1907-1948 & 241 \\
\hline $1902-1931$ & 114 & $1948-1949(d)$ & 263 \\
\hline $1931-1934(a)$ & 143 & $1949-1950$ & 0 \\
\hline $1934-1936$ (b) & 126 & $1950-1960(e)$ & 71 \\
\hline $1936-1947$ (c) & 95 & $1960-1971$ & 16 \\
\hline 1947-1959 & 50 & & \\
\hline \multicolumn{4}{|c|}{$\begin{array}{l}\text { (a) } 1931 \text { exploitation de } 29 \mathrm{~km} \text { de lignes affermées. } \\
\text { (b) } 1934 \text { fermeture de } 17 \mathrm{~km} \text { de lignes concédées. } \\
\text { (c) } 1936 \text { fermeture de } 31 \mathrm{~km} \text { de lignes affermées. } \\
\text { (d) } 1948 \text { desserte d'une ligne affermée de } 22 \mathrm{~km} \text { fermée en } 1949 \text { en même temps } \\
\text { que tout le réseau du département. } \\
\text { (e) } 1950 \text { exploitation de deux lignes affermées respectivement fermées en } 1960 \\
\text { et } 1971 .\end{array}$} \\
\hline
\end{tabular}


Une autre grande entreprise mérite une attention particulière.

\section{$>$ La Société générale des chemins de fer économiques ${ }^{5}$}

Le réseau de la SGCFE offre des ressemblances avec celui des CFD. Il associe des lignes d'intérêt général et des lignes d'intérêt local, des CFIL et des TVM, des lignes concédées et des lignes affermées, des lignes à voie normale et des lignes à voie métrique. Le réseau concédé CFIL et TVM confondus compte $1774 \mathrm{~km}$ en 1911, auxquels s'ajoutent $174 \mathrm{~km}$ de concessions d'intérêt général ; un réseau affermé de $455 \mathrm{~km}$ complète l'ensemble, soit en tout $2403 \mathrm{~km}$.

\section{Réseau concédé et réseau affermé en 1911}

Une seule ligne héritée de la période antérieure à la loi de 1880 est exploitée sous le statut de CFIL 1865 (Saint-Symphorien à Nizan et Sore). Les lignes de Seine-et-Marne et de Bordeaux à Camarsac bénéficient du statut de TVM. Le réseau de Gironde et des Landes est le premier mis en service avec $334 \mathrm{~km}$ entre 1884 et 1890 ; les $326 \mathrm{~km}$ du réseau de la Somme sont ouverts au public entre 1887 et 1892 ; le premier est à voie normale, le second à voie métrique. Les discussions des conseils généraux commandent le rythme de la construction, hâtif dans l'Allier (1887-1892), tardif dans le Cher et la Nièvre (1903-1908). Pour chacun de ces réseaux, on retiendra la concentration dans le temps de l'ouverture des lignes en cinq à six ans, qui n'est suivie que de compléments limités ; c'était un gage de saine gestion, qui supposait, à l'amont, la capacité d'un conseil général d'avoir une vision d'ensemble de l'équipement du département; dans ces conditions, la SGCFE pouvait faire la preuve de son efficacité. On compte encore plus de $100 \mathrm{~km}$ en Seine-et-Marne et dans le Nord et quelques courtes lignes isolées, réparties dans quatre départements ; en tout, la SGCFE a des concessions dans douze départements.

La SGCFE exploite parallèlement un réseau affermé de $455 \mathrm{~km}$. Le principal contrat d'affermage de l'époque est signé dès 1886 par l'Ouest: il porte sur le Réseau breton dont $375 \mathrm{~km}$ sur 422 prévus fonctionnaient en 1911 ; il concerne l'étoile de Carhaix avec ses cinq liaisons. Cet ensemble est classé d'intérêt général ; le gouvernement souhaitait s'engager, comme en Corse ou dans le Vivarais pour permettre

5- La documentation sur cette entreprise provient des archives que Monsieur Jacquot a remarquablement conservées et classées. D'autres fonds (archives de la CGEA) sont déposés aux Archives Nationales (Centre des archives du Monde du travail, voir p. 65); la CFTA conserve à Carhaix des fonds spécifiques au réseau breton (voir A. Le Guyader, RHCF 24-25, p. 328-341). Voir aussi J. Davies, «Les "Économiques", enfants de la III République ", Correspondances, revue d'histoire ferroviaire, $\mathrm{n}^{\circ}$ 1, 2002, p. 17-25 (traduit de l'anglais par J.-P. Vergez-Larrouy). 
le développement économique de la Bretagne intérieure qui souffrait de son enclavement; par mesure d'économie, la voie métrique a été choisie. Quatre lignes, en tout $80 \mathrm{~km}$, sont aussi affermées à la SGCFE, parfois en prolongement d'une ligne concédée : tel est le cas de la section de Bussy à Ercheu $(13 \mathrm{~km})$, qui se poursuit en direction de Doullens. Nord et PLM et deux autres sociétés sont à l'origine de ces opérations.

\section{L'évolution du réseau entre 1911 et 1933}

Entre 1911 et 1933, le développement du réseau par ouverture de nouvelles liaisons est limité ; l'exemple de ces années est significatif : en 1911, la société met deux lignes en service ${ }^{6}$ et a $68 \mathrm{~km}$ en chantier ${ }^{7}$; en 1933, aucune ouverture n'est programmée, $43 \mathrm{~km}$ sont en construction $^{8}, 74 \mathrm{~km}$ détruits pendant la guerre sont dans l'attente d'une problématique reconstruction. En revanche, les prises de contrôle, les affermages se multiplient, permettant une extension du réseau, à peine contrariée par quelques fermetures et rétrocessions : la ligne de Hondschoote à Bray-Dunes $(15 \mathrm{~km})$ est exploitée entre 1921 et sa fermeture en 1929 ; celle de Don-Sainghin à Fromelles $(18 \mathrm{~km})$ de 1920 à $1927^{\circ}$; la société a en fermage en 1921 les $120 \mathrm{~km}$ de la Compagnie des chemins de fer du Cambrésis, qui lui seront rétrocédés dès 1924.

La comparaison des inventaires des lignes en 1911 et 1933 montre la progression spectaculaire du réseau, de $53,5 \%$, soit un gain de $1281 \mathrm{~km}$; la société règne sur $3673 \mathrm{~km}$ de voies ferrées. Les réseaux de l'Anjou (315 km) en 1928 et de l'Hérault (212 km) en 1929 entrent dans son domaine. Dans l'Est, la société exploitait deux lignes isolées, en tout $66 \mathrm{~km}$ en 1911 ; vingt-deux ans plus tard, elle a pris en charge un vaste ensemble de relations dans la Meuse $(305 \mathrm{~km})$ en 1923, puis entre 1924 et 1926 diverses lignes électriques dans la région de Gérardmer. 1933 est une année charnière : une véritable politique de fermeture des lignes déficitaires n'est pas pratiquée, le transfert de trafic du rail à la route n'est que timidement amorcé (chapitre $\mathrm{x}$ ).

6- Liaisons de Digoin au Donjon (24 km) et de Cambrai à Lourches $(25 \mathrm{~km})$.

7- $15 \mathrm{~km}$ pour raccorder les lignes de l'Oise et de la Somme, $52 \mathrm{~km}$ dans le Nord, $1 \mathrm{~km}$ pour achever la ligne Digoin-Le Donjon mise en service dans l'année.

8- $21 \mathrm{~km}$ entre Saint-Amand-en-Puisaye et Saint-Sauveur, $13 \mathrm{~km}$ dans le Nord, $9 \mathrm{~km}$ entre Subreville et Apremont.

9- L'histoire complexe de cette ligne mériterait une analyse précise : elle est concédée à M. Michon, puis exploitée par la Compagnie des chemins de fer du nord de la France ; cette demière en confie l'exploitation en 1920 à la SGCFE qui la rétrocède en 1927 à la Compagnie des chemins de fer du nord de la France ; en 1933, la ligne est prise en charge par la Compagnie des chemins de fer secondaires jusqu’à la fermeture en 1951. 


\section{La rétraction du réseau ferré 1934-1950}

La période suivante nous conduit au début des années cinquante ; elle est celle de l'application des principes que nous venons de définir. La guerre n'est qu'une parenthèse dans une évolution irréversible. Les camions et les autocars poussifs au gazogène donnent un intérêt tout passager à la voie ferrée. En 1950, le réseau de la SGCFE est encore de $3375 \mathrm{~km}$, mais les circulations ferroviaires sont limitées à $2068 \mathrm{~km}$, $1307 \mathrm{~km}$ ne disposent que de services routiers. Le réseau ferré depuis 1933 s'est rétracté de $1605 \mathrm{~km}$, soit 43,7\% en dix-sept ans, et encore ce chiffre cache-t-il des réalités contradictoires. Les effectifs de camions et autocars utilisés sur divers réseaux de la société illustrent l'importance accordée à l'emploi des techniques routières.

La transformation du réseau de la société se réalise en deux étapes séparées par la guerre. Entre 1936 et 1939 sont affectés par des transferts de trafic du rail à la route, rarement par des cessations d'activités, les réseaux de la Meuse, de la Nièvre et quelques lignes vosgiennes, en tout $588 \mathrm{~km}$. Des mutations analogues se produisent entre 1946 et 1951, touchant $1342 \mathrm{~km}$ des réseaux de l'Anjou, de l'Allier, du Cher, de Seine-et-Marne et des chemins de fer de grande banlieue. Dans la même période, la SNCF afferme à la SGCFE $502 \mathrm{~km}$ répartis en deux réseaux, dits du Nivernais $(225 \mathrm{~km})$ et de Franche-Comté $(277 \mathrm{~km})^{10}$. Ces lignes d'intérêt général sont à voie normale. Dans l'ensemble, les réseaux et lignes à voie normale (Gironde, Hérault et quelques lignes isolées) ont résisté plus longtemps que les autres : leur part n’a cessé de croître au sein de la société : $12 \%$ en 1911, $16 \%$ en 1933, $57 \%$ en 1950 où ce réseau est long de $1173 \mathrm{~km}$ contre 893 à la voie métrique. Entre 1933 et 1950, on a assisté à des mouvements contradictoires : transferts de service sur route, contrats pour prendre en charge de nouvelles lignes ferrées ; le cas de la Nièvre est exemplaire avec $225 \mathrm{~km}$ de lignes nouvelles à écartement normal et $212 \mathrm{~km}$ de voie métrique abandonnés.

Ces constatations invitent à se poser des questions. Quel intérêt la SGCFE et la Compagnie des CFD trouvaient-elles à prendre en charge des lignes déficitaires de la SNCF à un moment où l'exploitation de ces liaisons par voie ferrée était mise en cause ? Dans l'état actuel du dépouillement des archives de ces compagnies, il n'est pas possible de préciser quelles ont été dans ce processus leur stratégie et leur autonomie par rapport à l'État. Des changements intervenaient-ils dans les modalités

10- Nivernais : lignes de Clamecy à Nevers, à Cercy-la-Tour et Gilly, de Tamnay à Château-Chinon.

Franche-Comté : lignes de Troyes à Chalindrey et Langres à Poinson-Beneuvre. 
d'exploitation des lignes? Quelles étaient les conséquences pour les usagers et pour les cheminots? Un regard plus général sur cette politique d'affermage menée par les grandes compagnies et poursuivie par la SNCF mériterait une étude approfondie.

\section{Les ultimes transformations de la SGCFE}

Les tendances déjà constatées s'affirment dans la période suivante (1952-1962). Le réseau total est de $2685 \mathrm{~km}$, en régression de $20 \%$ par rapport à 1951, soit une perte de $690 \mathrm{~km}$. Le réseau des services routiers de voyageurs avec $1259 \mathrm{~km}$ est pratiquement resté stable ; le réseau ferré n'a plus que 1426 km contre 2608 , ce qui représente une réduction de l'ordre de $45 \%$. Les lignes qui avaient résisté aux vagues de fermetures sont touchées à leur tour dans la Meuse, la Seine-et-Oise, le Centre où les deux lignes d'intérêt général de Sancoins à Lapeyrouse et de La Guerche à Châteaumeillant sont condamnées $(141 \mathrm{~km})$. La part de la voie normale augmente encore $(61 \%)$ et règne sur les réseaux de Gironde et de l'Hérault ${ }^{11}$, ainsi que sur les lignes nouvellement affermées du Nivernais et de Franche-Comté. La voie métrique intéresse le réseau breton et quelques courtes sections en Seineet-Oise et en Seine-Maritime. Au $1^{\text {er }}$ janvier 1962, la SNCF afferme à la société les $95 \mathrm{~km}$ à voie métrique du réseau de la Corrèze. Les lignes concédées à la SGCFE par l'État ou par les départements, aux origines de la société, comptent $427 \mathrm{~km}$ contre 999 pour les lignes affermées par la SNCF. Sur le plan de l'exploitation ferroviaire, la société se transforme en prestataire de service.

Pendant ces années, l'exploitation par route prend de l'importance : en douze ans, le nombre d'autocars augmente de $38 \%$, celui des camions de $156 \%$. Plus de vingt centres d'exploitation du trafic marchandises sont en activité, notamment à Lyon, ClermontFerrand, Montluçon, Moulins, Bourges, Amiens, Angers, Rouen, Nantes, Cholet...; on retrouve plusieurs des localisations correspondant au développement des anciens réseaux ferrés à l'origine de la SGCFE.

\section{$>$ La Compagnie générale des chemins de fer vicinaux (CGCFV)}

La compagnie exploite en 1911 un réseau à voie métrique formé d'une ligne de CFIL 1865 unissant Gray à Gy, d'un réseau de CFIL 1880 couvrant la Haute-Saône avec quelques prolongements dans le Doubs et le Jura, enfin d'une ligne de TVM reliant Lons-le-Saunier à

11- La fermeture du réseau de l'Hérault date de 1968, celui de la Gironde de 1978, ceux à voie métrique de la Somme intervient en 1968 et celle de Bretagne en 1967 ; sur ce réseau breton, $90 \mathrm{~km}$ sont demeurés en exploitation après être portés à écartement normal. 
Saint-Claude avec embranchements, respectivement 22, 491 et $142 \mathrm{~km}$; le total est de $655 \mathrm{~km}$. Cette longueur est plus proche de celle des réseaux départementaux que de celles de la SGCFE ou des CFD. Si nous associons la CGCFV aux deux autres grandes sociétés, c'est que le kilométrage ne saurait être le seul critère à prendre en compte. Cette entreprise n'est qu'un élément au sein d'un puissant groupe : à ce titre, dans une autre approche, elle a une place justifiée aux côtés des deux principales entreprises de chemins de fer secondaires.

\section{. La concentration dans le secteur des chemins de fer secondai- res (CFIL et TVM) d'après le kilométrage exploité (tabl. 9)}

La concentration se traduit dans la part du kilométrage contrôlé par quelques grandes compagnies. Le contraste est saisissant entre les trois compagnies majeures de CFIL, 3,4\% du total d'entre elles exploitant pratiquement le tiers du réseau et le tiers des petites compagnies se satisfaisant de $2,5 \%$ des kilomètres en service : la moyenne de leur réseau s'établit à $1013 \mathrm{~km}$ pour les premières, à 8 pour les secondes.

La situation n'est pas semblable pour les TVM. Aucune compagnie n'atteint $400 \mathrm{~km}$; plus de la moitié des kilomètres en service dépend de sociétés disposant de 100 à $299 \mathrm{~km}$, contre moins du tiers dans le cas des CFIL. Mais les petites entreprises sont plus nombreuses, 45,2 \% ; elles disposent de $7 \%$ du kilométrage. La concentration est visible, mais elle s'opère au profit d'entreprises moins puissantes que dans le cas des CFIL.

La structure de l'ensemble des chemins de fer secondaires fait apparaitre pour tous les régimes quelques grandes entreprises contrôlant une part du réseau sans commune mesure avec leur nombre à côté d'une légion de modestes entrepreneurs ; simple apparence pour ceux d'entre eux qui participent aux conseils d'administration de multiples sociétés ou reçoivent le soutien de milieux financiers et de certains grands réseaux comme le Nord. Cette situation fait inévitablement penser au transport routier d'aujourd'hui dont la structure éclatée est toujours mise en avant, mais dont la réalité de la concentration ressort de toute statistique sur la répartition entre grandes et petites entreprises de l'investissement, du chiffre d'affaires ou du nombre de salariés.

L'action de ces entreprises a conduit à la naissance d'un réseau de chemins de fer secondaires moitié moins long que le réseau d'intérêt général. 
Tableau 9. Structure du secteur des CFIL 1880 et des TVM

\begin{tabular}{|c|c|c|c|c|c|c|}
\hline \multicolumn{7}{|l|}{ 1- CFIL } \\
\hline & $>500 \mathrm{~km}$ & $300-499$ & $200-299$ & $100-199$ & $20-99$ & $<20$ \\
\hline Nombre de compagnies & 13 & 4 & 6 & 12 & 32 & 30 \\
\hline $\begin{array}{l}\text { Pourcentage des } \\
\text { compagnies }\end{array}$ & 3,4 & 4,5 & 6,8 & 13,8 & 36,8 & 35 \\
\hline $\begin{array}{l}\text { Nombre de kilomètres } \\
\text { exploités }\end{array}$ & 3039 & 1475 & 1367 & 1628 & 1650 & 241 \\
\hline Pourcentage des kilomètres & 32,3 & 15,8 & 14,6 & 17,3 & 17,5 & 2,5 \\
\hline $\begin{array}{l}\text { Moyenne de kilomètres par } \\
\text { compagnie }\end{array}$ & 1013 & 368 & 227 & 135 & 51 & 8 \\
\hline \multicolumn{7}{|l|}{ 2- TVM } \\
\hline Nombre de compagnies & & 4 & 7 & 12 & 29 & 43 \\
\hline Pourcentage & & 4,2 & 7,3 & 12,6 & 30,7 & 45 \\
\hline $\begin{array}{l}\text { Nombre de kilomètres } \\
\text { exploités }\end{array}$ & & 1414 & 1676 & 1895 & 1229 & 474 \\
\hline Pourcentage des kilomètres & & 21,1 & 25 & 28,3 & 18,6 & 7 \\
\hline $\begin{array}{l}\text { Moyenne de kilomètres par } \\
\text { compagnie }\end{array}$ & & 353 & 239 & 157 & 42 & 11 \\
\hline
\end{tabular}

\section{- Les compagnies de tramways pour voyageurs seulement ou pour voyageurs bagages et messageries (TV - TVB)}

Suivant les concessions accordées par les conseils municipaux, les compagnies de tramways ont des obligations de transport définies et différentes. Les tramways pour voyageurs, bagages et messageries se combinent avec la desserte assurée par les tramways pour voyageurs seulement dans certaines villes, dans d'autres les élus ont choisi entre les deux possibilités. Ces deux types de tramways débordaient éventuellement le cadre urbain, parcourant les banlieues, assurant le cas échéant la liaison entre deux villes. Les TVB étaient appréciés des voyageurs, surtout de ceux qui étaient accompagnés des volumineuses malles en usage à l'époque. Seulement $16 \%$ des lignes dépassaient 30 km, $39 \%$ comptaient entre 11 et $30 \mathrm{~km}, 45 \%$ moins de $11 \mathrm{~km}$.

Les premières concessions de TV portaient sur quelques kilomètres de lignes; des entreprises dans des villes modestes en sont restées à ce niveau. L'évolution démographique et spatiale des cités stimulant la demande, les conseils municipaux ont été conduits à octroyer de 
nouvelles concessions, tantôt renforçant la compagnie initiale, qui bénéficiera d'un monopole, tantôt favorisant la formation d'une nouvelle société. Dans les grandes villes, les autorités de tutelle, conscientes de la nécessité d'établir un système de transport public, concédaient un réseau de 10 à $30 \mathrm{~km}$, plus rarement 50 ou 60. En 1911, quatre villes de province seulement offrent un réseau compris entre 100 et $200 \mathrm{~km}$, seule Paris en compte plus de 500.

Dans quelques villes, ces structures ont résisté au temps ; dans d'autres les entrepreneurs ont étendu le champ de leur activité, soit en prolongeant leurs lignes à travers les banlieues immédiates, soit en créant des lignes de TVB atteignant des périphéries plus lointaines, ou poussant jusqu'aux campagnes voisines ; certaines compagnies ont établi leur contrôle sur les réseaux de plusieurs villes. Toutes ces initiatives tendaient à un même but : l'allongement du kilométrage exploité.

Enfin ce secteur d'activité est apparu suffisamment attractif aux milieux financiers pour pousser à la création de puissantes sociétés exerçant plusieurs métiers, notamment ceux de constructeur et exploitant de réseaux de TV. Ces organismes finissent par contrôler plusieurs centaines de kilomètres de lignes de tramways en service dans une multitude de villes.

Le kilométrage exploité est un critère de différenciation significatif pour déterminer un classement des entreprises de VFIL. Mais le kilométrage se combine avec des données plus subtiles pour arriver à une connaissance de la vie même des entreprises. Une autre approche est nécessaire.

\section{Une autre approche des entreprises}

Avant de proposer une typologie, rappelons le coût moyen de construction d'un kilomètre de ligne secondaire depuis les études jusqu'au jour de la mise en service; cette donnée conditionne le volume de capitaux qu'un entrepreneur doit être capable de réunir, déduction faite des subventions attendues. Les entreprises ont une inégale aptitude à faire face à cette obligation, permettant de faire d'un projet une réalité.

\section{. Les critères de différenciation entre les entreprises}

\section{$>$ Le coût de construction et la ventilation des postes de dépenses}

La construction au $\mathrm{km}$ d'une ligne de CFIL à voie étroite et unique est estimée à $80000 \mathrm{~F}$, d'une ligne de TVM à $50000 \mathrm{~F}$ pour un tracé dans une zone de difficultés ordinaires exigeant peu de travaux 
d'art ; ces valeurs, qui se rapportent à la période de 1890 à 1913, correspondent à la progression rapide du réseau. Le relief est un facteur important du coût, avec un autre paramètre : la valeur des terres agricoles. Ouvrages d'art et achats des terrains représentent entre 40 et $50 \%$ des dépenses d'infrastructures. On mesure combien le choix du TVM permet d'économiser sur les deux postes pesant le plus sur les dépenses de construction d'une ligne. La ventilation des dépenses de construction entre les principaux postes fait apparaittre une moyenne de $60 \%$ pour les infrastructures et de $40 \%$ pour les superstructures; le détail au sein des deux groupes est donné pour une ligne en Gironde, traversant une région viticole : on comprend la place tenue par les acquisitions de terrains (tabl. 10) ${ }^{12}$.

Tableau 10. Ventilation des dépenses entre les principaux postes à l'occasion d'une construction de voie ferrée

\begin{tabular}{|c|c|c|c|c|c|}
\hline \multicolumn{4}{|c|}{ Infrastructures } & \multicolumn{2}{|c|}{ Superstructures } \\
\hline Achat de terrains & $24 \%$ & Études & $6,1 \%$ & \multirow{2}{*}{$\begin{array}{l}\text { Voie, } \\
\text { ballastage, } \\
\text { règlement de } \\
\text { la plateforme }\end{array}$} & \multirow[b]{2}{*}{$54,2 \%$} \\
\hline Ouvrages d'art & $22 \%$ & Frais généraux & $6 \%$ & & \\
\hline Terrassements & $18 \%$ & $\begin{array}{l}\text { Passages à } \\
\text { niveau }\end{array}$ & $5,1 \%$ & Bâtiments & $35,5 \%$ \\
\hline $\begin{array}{l}\text { Consolidation des } \\
\text { terrassements }\end{array}$ & $9,5 \%$ & $\begin{array}{l}\text { Murs de } \\
\text { soutènement }\end{array}$ & $0,5 \%$ & $\begin{array}{l}\text { Personnel } \\
\text { d'études }\end{array}$ & $3,7 \%$ \\
\hline \multirow{4}{*}{$\begin{array}{l}\text { Déviations des } \\
\text { chemins et } \\
\text { rivières }\end{array}$} & \multirow{4}{*}{$8,4 \%$} & \multirow{4}{*}{ Dommages } & \multirow{4}{*}{$0,4 \%$} & Clôtures & $0,2 \%$ \\
\hline & & & & Télégraphe & $1,40 \%$ \\
\hline & & & & $\begin{array}{l}\text { Poteaux } \\
\text { kilométriques }\end{array}$ & $0,2 \%$ \\
\hline & & & & Divers & $4,80 \%$ \\
\hline \multicolumn{4}{|c|}{$100 \%$} & & $100 \%$ \\
\hline
\end{tabular}

Source : Agenda Dunod, 1909. Les lignes prises en compte dans le calcul de cette moyenne ne sont pas précisées.

\section{$>$ La surface financière}

Comme de nos jours, les coûts étaient fréquemment sous-évalués dans les devis initiaux. Les dépassements conduisaient les concessionnaires à rechercher une aide financière, en priorité auprès des concédants, en

12- P. Blanc, «Les Chemins de fer», 30édition, Agenda Dunod, Paris, 1909, 260 p. 
l'occurrence les conseils généraux, contraints de contracter de nouveaux emprunts. Le degré de confiance accordée au concessionnaire dans sa capacité à poursuivre les travaux déterminait de la part des conseillers généraux des réactions plus ou moins favorables à la demande de l'entreprise, en fonction de son assise financière. Des recours au marché financier étaient concevables si une entreprise trouvait un organisme disposé à accorder sa garantie à l'emprunt. La Compagnie du Nord a pratiqué cette politique pour éviter de développer son propre réseau ; elle y trouvait avantage en favorisant la construction et l'exploitation économiques de lignes secondaires dont la mission était de rabattre le trafic, au plus court, vers les gares de la grande compagnie ; ces liaisons ont surtout desservi les zones de production betteravière et des ensembles industriels insuffisamment irrigués par les voies du Nord.

La surface et la situation financières des entreprises sont des facteurs essentiels dans l'établissement d'une typologie.

\section{. Les divers types d'entreprises}

Nous laissons de côté les entreprises hasardeuses et sans avenir de la décennie soixante-dix du XIX ${ }^{e}$ siècle, qui ont débouché sur des faillites retentissantes; la plus spectaculaire a été celle de Philippart dont F. Caron a récemment rappelé l'histoire ${ }^{13}$. Notre attention se concentre sur des entreprises qui, à travers d'inévitables péripéties, ont construit, exploité une ligne ou un réseau dans la durée. Nous irons des entreprises les plus simples aux plus complexes, en retenant trois types.

\section{$>$ Les petites entreprises}

Ces entreprises exploitent une ou deux lignes dont la longueur totale se situe entre 3 et $80 \mathrm{~km}$. De courtes liaisons peuvent être intégrées au sein de réseaux étendus; elles ne sont pas l'objet de notre présent intérêt.

\section{L'exemple de la ligne d'Étainhus à Saint-Romain-de-Colbosc}

Un exemple typique de petite entreprise est donné par la société exploitant la ligne de $3 \mathrm{~km}$ de TVM à vapeur reliant la gare d'Étainhus sur la ligne de Rouen au Havre au bourg de Saint-Romain-de-Colbosc ; cette modeste localité de 1801 habitants en 1891 voulait rompre son isolement pour développer ses foires et ses marchés. Une société s'est constituée à l'initiative de notables locaux et havrais. La commune a apporté son soutien en décidant un prélèvement annuel de $1354,50 \mathrm{~F}$ pendant 50 ans. La société constituée en 1897 a construit, puis exploité

13- F. Caron, Histoire des chemins de fer en France, tome I, 1740-1883, Paris, Fayard, 1997, 700 p., p. 443-462. 
la ligne dès 1897. Les difficultés financières nées après 1920, avec la concurrence d'un service d'autobus, ont été compensées par une subvention du conseil général. Le service ferroviaire a été suspendu en 1929.

Arrêtons-nous sur les origines sociales et géographiques des fondateurs ${ }^{14}$ : un cultivateur d'Étainhus, un négociant et deux propriétaires de Saint-Romain-de-Colbosc, deux négociants du Havre. Ce sont bien des hommes directement intéressés au fonctionnement de la ligne qui ont été à l'origine du projet ; cette réalisation locale est concevable, car elle suppose la mobilisation de capitaux limités : la société avait un capital de $150000 \mathrm{~F}$ divisé en 300 actions de 500 F. Nous sommes confrontés au problème que nous venons de poser: si le négociant de Saint-Romain-de-Colbosc a des chances d'être un grossiste ou un semi-grossiste, dont l'activité est tournée vers l'approvisionnement du bourg en quincaillerie, produits, textiles..., qui sont les négociants du Havre? De simples concurrents du précédent ou des importateurs de café ou de coton, dont le port était au centre d'un commerce actif, à l'affût de placements financiers qui, en 1897, leur paraissaient intéressants ? Interrogation aussi au sujet des propriétaires : leur résidence rurale fait pencher en faveur de propriétaires de domaines agricoles, soucieux de bénéficier de facilité de circulation et pouvant avoir intérêt à de nouvelles possibilités de transport des marchandises. Quel est aussi ce cultivateur susceptible d'investir dans une telle opération ? On souhaiterait des monographies qui permettent de répondre à ce type d'interrogations.

La compagnie se satisfaisait de disposer de trois locomotives, quatre voitures à classe unique, deux fourgons et trois wagons. Elle était dirigée par quatre administrateurs et directeurs et comptait 13 agents comme personnel d'exécution. Ces caractéristiques sont très représentatives des entreprises exploitant un kilométrage très réduit.

\section{Données générales}

\section{. Le capital engagé, administrateurs et sièges sociaux}

Les petites entreprises de ce modèle sont encore nombreuses en 1911. Lorsque le kilométrage à construire augmentait, le capital engagé s'élevait, mais il dépassait rarement le demi-million de francs ; il était divisé en un nombre variable d'actions dont les prix d'émission étaient fixés entre 100 et $500 \mathrm{~F}$ (tabl. 11).

14- P. Manneville «Les chemins de fer d'intérêt local à la fin du XIX siècle et au début du $\mathrm{xx}^{\mathrm{e}}$ siècle : l'exemple d'un département, la Seine-Inférieure ", in Les Transports de 1610 à nos jours, Actes du $104^{e}$ Congrès des sociétés savantes, Paris, BN, 1980, tome I, p. 271-284. 


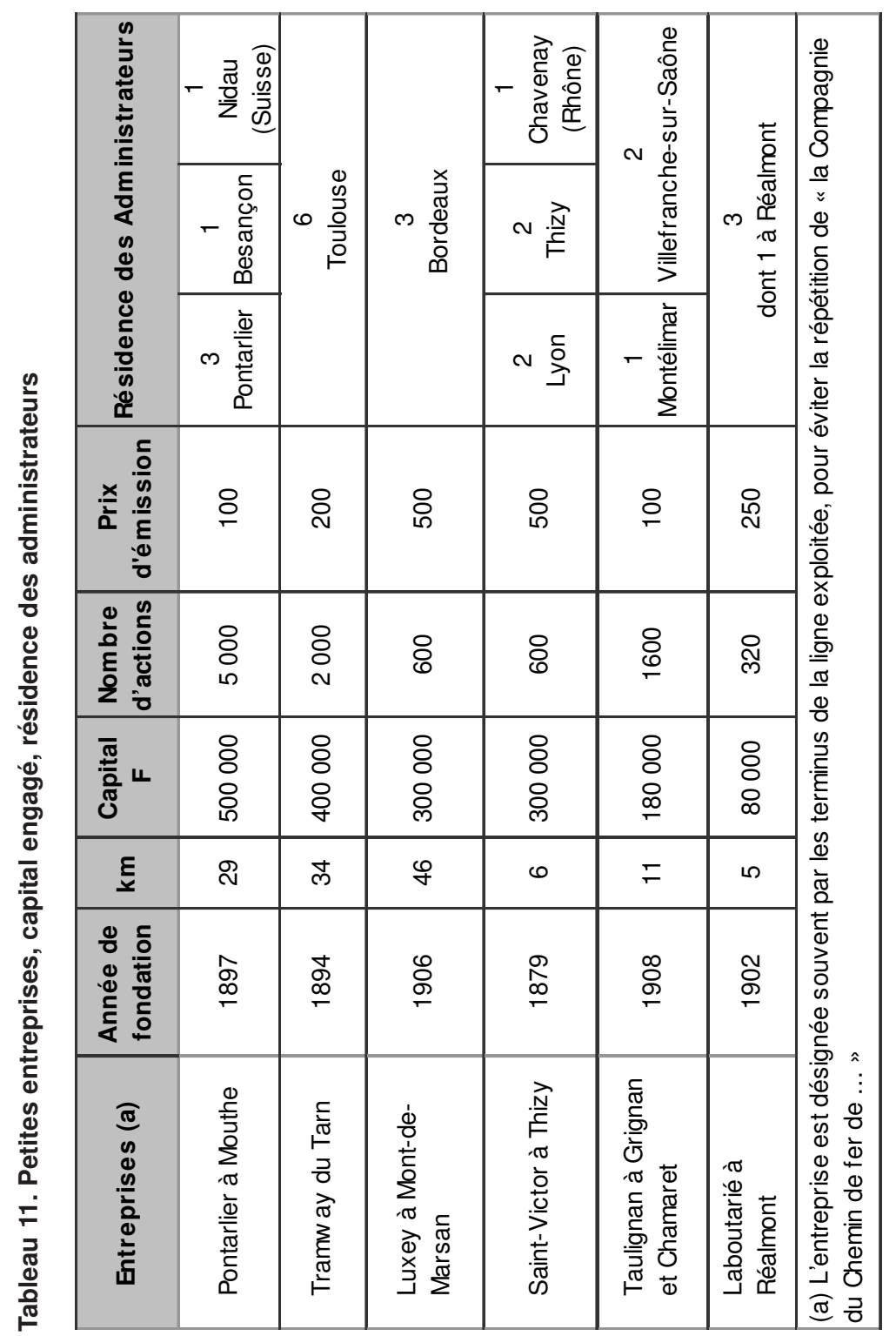


Ces entreprises avaient souvent une majorité d'administrateurs provinciaux. Leur siège social était à proximité de leur lieu d'exploitation (tabl. 12).

Tableau 12. Localisation des sièges sociaux de petites entreprises

\begin{tabular}{|l|l|}
\hline \multicolumn{1}{|c|}{ Entreprises } & \multicolumn{1}{c|}{ Sièges } \\
\hline Vallée de Celles & Raon-l'Étape \\
\hline Pithiviers à Toury & Pithiviers \\
\hline Reins à Amplepluis & Amplepluis \\
\hline Saint-Victor à Cours & Bourg-de-Thizy \\
\hline
\end{tabular}

Source : Recueil de tarifs "Grande vitesse", Chaix, 1912.

Ce modèle souffre des exceptions. Les entreprises choisissent l'emplacement de leur siège social et de leur direction opérationnelle ${ }^{15}$; elles déménagent parfois de la province à Paris. Certaines se regroupent à une même adresse. Ces données ont l'avantage d'être immédiatement perceptibles : elles pourraient sembler insignifiantes, or elles sont révélatrices de relations d'interdépendance dont on peut chercher la nature profonde. Le but de ces regroupements n'a pas pour objet majeur d'économiser sur les salaires des concierges, femmes de ménage ou du personnel de bureau; il est de permettre une unité de direction; le regroupement traduit la participation de mêmes administrateurs aux conseils de plusieurs compagnies. Le siège de la compagnie exploitant la ligne de Challans à Fromentine $(25 \mathrm{~km})$ est au 11, boulevard Malesherbes, à Paris; le siège voisin de la compagnie de la ligne de Tarascon-sur-Ariège à Auzat (6 km) est au 124, rue de la Boétie, à Paris, les administrateurs sont parisiens. Encore à Paris, au 69, avenue de la Grande-Armée, sont rassemblés les sièges sociaux de trois entreprises : Andelot à Levier $(21 \mathrm{~km})$, Chemins de fer du Doubs $(87 \mathrm{~km})$ et de Cormeilles à Glos-Monfort et extension (69 km); ces deux dernières se situent dans la fourchette haute de ce type d'entreprises, d'après le kilométrage qu'elles exploitent : cela explique sans doute l'intérêt que leur a porté un homme qu'on retrouve dans les activités liées aux réseaux secondaires, Laborie ${ }^{16}$. Hors ce cas, les petites entreprises ont peu

15- L'étude de la localisation des sièges sociaux a été conduite au départ d'un document Chaix de 1912 consacré aux tarifs GV de diverses compagnies secondaires.

16- La compagnie du chemin de fer d'Andelot à Levier a été intégrée à celle des Chemins de fer du Doubs dans l'entre-deux-guerres. 
attiré les personnalités les plus représentatives de ce secteur d'activités. Monsieur Ortal, administrateur de la Compagnie de chemin de fer de Luxey à Mont-de-Marsan, réapparaît seulement comme bénéficiaire de l'affermage de deux lignes de modeste importance : La Teste à Cazaux et le tramway balnéaire d'Arcachon.

Le statut de TVM était généralement retenu pour les économies qu'il permettait de réaliser. Un même lieu abritait souvent le siège social et la direction des services. Les points d'arrêt facultatifs sans équipement ni personnel, les haltes aux bâtiments sommaires l'emportaient sur les stations aménagées.

\section{Les dirigeants}

La connaissance des hommes qui ont fondé, dirigé, animé les entreprises permet d'identifier leur origine sociale, professionnelle, géographique variable en fonction des types d'entreprises. Certains réussissent, d'autres non. En dehors des capacités propres à chaque individu, les échecs peuvent être imputés, pour certains, à l'absence d'un système de relations étoffé avec les milieux politiques et financiers, pour d'autres à une méconnaissance des difficultés techniques propres à la construction de voies ferrées ou aux problèmes de gestion économique d'une ligne ou d'un réseau. L'illusion sur les perspectives de trafic entretenue par le milieu local a trompé plus d'un entrepreneur en conduisant à de sérieuses déconvenues.

Les professions des administrateurs sont à retenir. Mais il y a des faiblesses dans l'information. On retrouve fréquemment la mention «négociant»; sans doute le terme désigne-t-il celui qui fait du commerce à un niveau supérieur à celui du petit commerçant en contact avec les particuliers. Le semi-grossiste de sous-préfecture et l'importateur de matières premières ou de produits alimentaires peuvent être désignés par le même terme. Une ambiguité de même essence recouvre une autre catégorie largement représentée dans les conseils d'administration, les " propriétaires »; les rentiers étaient nombreux jusqu'à la Première Guerre mondiale, mais leur disponibilité financière n'était pas identique, leurs intérêts non plus. Le rentier rural, vivant sur ses terres, pouvait avoir un intérêt direct à la construction de chemins de fer secondaires et l'encourager. Le citadin avec ses immeubles et ses valeurs mobilières était à la recherche de placements productifs. Le premier était plus méfiant que le second face aux opérations financières. Enfin l'étude les noms permet de repérer des personnalités qu'on retrouve dans divers conseils d'administration. 


\section{Le personnel et matériel}

Dans les chapitres vi et VII, nous tentons une synthèse des questions de personnel et de parc de matériel ; le but est d'établir des comparaisons fondées sur des indices du nombre d'agents pour $10 \mathrm{~km}$ et du volume du parc total au $\mathrm{km}^{17}$. Cette démarche ultérieure ne saurait nous interdire d'évoquer maintenant, à propos de cas concrets, le niveau des équipements en matériel et des effectifs en personnel propres à chaque type d'entreprise : ces données sont respectivement des facteurs importants des dépenses d'investissements et d'exploitation.

Le personnel variait dans sa composition d'une entreprise à l'autre : sur un effectif total de 18 personnes, six relevaient de la catégorie «administrateurs, directeurs d'administration centrale » pour la Compagnie du chemin de fer de Pont-de-Vaux à Fleurville-Pont-deVaux, les proportions étaient de 1 à 26 pour la liaison de Challans à Fromentine, de 4 pour 55 pour la ligne de Pontarlier à Mouthe. Il n'existe pas de rapport entre le kilométrage exploité et l'effectif du personnel : les compagnies exploitant les lignes de Cassel-gare à Casselville $(4 \mathrm{~km})$ et de Taulignan à Grignan $(11 \mathrm{~km})$ requièrent toutes deux les services de 12 personnes. Lorsqu'on examine la répartition des agents aux divers niveaux de la hiérarchie, on constate que de nombreuses fonctions ne sont pas remplies.

Un autre trait commun à ces entreprises est l'utilisation d'un matériel peu nombreux. Pour assurer la continuité du service, les entreprises se dotent au moins de deux locomotives, quelquefois de quatre, trois semble le choix le plus courant. La traction électrique par fil aérien est utilisée sur la ligne de Pierrefitte-Nestalas à Cauterets (CFIL 1880); une "cavalerie », suivant le terme consacré, de neuf chevaux répond aux besoins sur les $5 \mathrm{~km}$ de Laboutarié à Réalmont. Le parc de matériel est peu fourni : sauf sur la ligne de Cauterets, avec 26 voitures, les autres compagnies se satisfont de deux à huit voitures : les voitures de $1^{\text {te }}$ classe sont exceptionnelles, les voitures de $2^{\mathrm{e}}$ classe sont souvent en service, mais la préférence va aux voitures mixtes dont l'utilisation permet de réduire le tonnage des trains; sur les CFIL à voie normale circulent encore quelques voitures de $3^{e}$ classe; deux fourgons sont utilisés. Le nombre des wagons est généralement compris entre 20 et 30, mais il peut baisser au-dessous de dix ; quatre dont une automotrice affectée aux seules marchandises sur la ligne de Cassel ; une plate-forme à deux roues attachée à la voiture fait office de wagon

17- Cf. ci-dessous tabl. 35 et 36 p. 205 et 206. 
entre Laboutarié et Réalmont. Les entreprises de ce niveau ne sont pas en mesure de financer des investissements importants dans le matériel, ni dans son renouvellement.

Lorsque la longueur des lignes à construire s'allonge, les initiatives locales ne permettent plus de conduire un projet à bonne fin ; les moyens financiers à réunir sont trop importants; la petite entreprise n'est pas viable.

\section{$>$ Les entreprises à assise départementale}

Ce second type d'entreprise exploite des réseaux dont la longueur varie entre cent et quatre cents kilomètres. Ces réseaux s'inscrivent dans un cadre départemental avec d'éventuels et brefs prolongements dans les départements limitrophes. Ils sont établis à l'initiative des conseils généraux. Chaque département a sa propre histoire, mais des points communs existent ; à travers l'exemple du département de l'Indre, on peut suivre le long processus qui conduit à la décision de construire un réseau ${ }^{18}$.

\section{L'exemple de la Compagnie des tramways de l'Indre}

Trois compagnies desservent le département ; les CFD exploitent un prolongement de quelques kilomètres de leur réseau d'Indre-et-Loire pour atteindre Ecueillé ; la Compagnie du Blanc-Argent dispose d'une ligne circulant du Blanc à la limite du Cher; elle n'est pas le fruit de la volonté du conseil général ; nous évoquons plus loin son histoire complexe ${ }^{19}$. Enfin, la Compagnie des tramways de l'Indre correspond au type d'entreprise que nous voulons étudier.

Bernard Moreau a évoqué les trente ans de débats consacrés aux chemins de fer secondaires par l'assemblée départementale entre 1882 et 1913. Un premier projet de six lignes, jugé irréaliste par le Conseil des Ponts, est abandonné. Au terme de onze ans, en 1893, la décision de construire $182 \mathrm{~km}$ est arrêtée. Les trois lignes prévues sont isolées les unes des autres ; les liaisons de la préfecture avec les campagnes ne sont améliorées qu'en direction de Valençay. Un réseau cohérent, comme ont su l'établir certains départements, reste à coordonner ; les conseillers généraux, voulant corriger leur erreur, proposent cinq lignes en 1903, en 1907 la construction de onze lignes ; en 1909, ils limitent leur ambition à la réalisation de sept lignes ; les débats se poursuivent jusqu’à la guerre qui rend tous les projets caducs. Les conseillers du département n'ont pas eu une vision d'ensemble, n'ont jamais défini ce qu'ils attendaient

18- B. Moreau, Le Tacot, petit train berrichon, 2 tomes, Châteauroux, 1988, 122 p. et Issoudun, 1989, 176 p., p. 7-10.

19- cf. ci-dessous p. 286. 
d'un réseau ; ils n'ont cessé de modifier leur projet. Les luttes entre les cantons pour obtenir prioritairement une ligne ont sans doute paralysé le conseil.

Les grandes compagnies tentaient toujours d'évaluer le trafic probable d'une ligne à construire : elles utilisaient, dans les années 18601870, la méthode des comptages de la circulation routière ${ }^{20}$, puis la méthode comparative, progressivement affinée : le trafic était évalué en fonction de celui d'une ligne en service dans la région; d'autres méthodes étaient utilisées : on rapportait le nombre de voyageurs à la population d'une zone englobant $5 \mathrm{~km}$ de chaque côté du tracé ; on estimait à $10 \mathrm{~km}$ la distance à laquelle une ligne n'avait plus aucun pouvoir d'attraction ; on évaluait le trafic en fonction de la population des communes desservies à raison de deux à quatre voyageurs et de une à deux tonnes de marchandises, mouvement industriel en plus, par habitant et par an ; l'analyse du milieu économique était prise en compte.

Sauf exception, les compagnies secondaires ne se sont pas entourées de tant de précautions. Ainsi la Compagnie des tramways de l'Indre a précisé la population des communes traversées par la ligne de Châteauroux à Valençay, à ses yeux les seules concernées ; pour l'agglomération de Châteauroux-Déols, 28000 habitants, elle en a retenu 14000 comme clients potentiels, sans qu'on trouve une explication à ce choix d'éliminer la moitié des habitants; il ne semble pas qu'il y ait eu davantage d'estimation du nombre de voyageurs par an et par habitant en fonction de la population des communes desservies. Pour les marchandises, les prédictions des hommes politiques, des journalistes, des pamphlétaires l'emportaient sur l'analyse du milieu économique effectuée par les grandes compagnies. Cependant, le nombre d'animaux présentés dans les foires et marchés, le développement de la production des mines de Chaillac, le trafic potentiel en correspondance avec le PO, dans un sens les expéditions de blé, dans l'autre l'approvisionnement en charbon des bourgs, étaient des données permettant d'avoir une idée de l'activité de la ligne dans l'avenir.

L'appel d'offres est lancé. Le traité de concession impose trois trains quotidiens, quatre si les recettes le permettent. Le revenu doit être de $9,97 \%$ avec un minimum garanti de $7 \%$. Douze soumissionnaires adressent des dossiers. Le préfet en écarte cinq pour manque d'honorabilité,

20- On prenait en compte le nombre de voyageurs et, pour les marchandises, le nombre de colis comptabilisés sur les routes tracées dans la direction de la voie ferrée à construire. La méthode a été abandonnée parce qu'elle pronostiquait un trafic de l'ordre du double de celui constaté après la mise en service de la ligne. Agenda Dunod, ouvr. cité, p. $15-20$ 
un pour non conformité au projet, puisqu'il propose des voitures à vapeur sur route et non sur chemin de fer. Les candidats retenus sont déjà concessionnaires dans d'autres départements, tels Jeancard, Faugère, Chatelin, ou des fabricants de matériel de chemin de fer; c'est un entrepreneur de travaux publics à la tête de la Compagnie générale de la construction de Saint-Denis qui reçoit la concession; une partie des travaux est l'œuvre de sous-traitants locaux. Un emprunt de $4816000 \mathrm{~F}$ a été contracté auprès de la Caisse de retraite pour la vieillesse au taux de 3,75\%. Le prix du km fixé à $36000 \mathrm{~F}$ s'est élevé à $46600 \mathrm{~F}$ par suite du relèvement du prix du fer. Le conseil général a voté une subvention de $320000 \mathrm{~F}$ pour régler la question; les constructeurs se tournaient généralement vers l'autorité de tutelle pour régler leurs problèmes financiers. Suivant un schéma qu'on retrouve fréquemment, le constructeur participe à la création d'une compagnie qui bénéficie de la rétrocession et assurera l'exploitation, ici la CTI. Cette société anonyme dispose d'un capital de un million de francs divisé en 2000 actions réparties entre onze actionnaires, 1110 pour le président Seydoux, 250 pour le constructeur de la ligne, 50 pour le directeur de la compagnie. Les autres actionnaires sont deux industriels respectivement de Laon et du Cateau, trois rentiers, un notaire, un voyageur de commerce, un officier commandant. Neuf actionnaires sont parisiens ou de la toute proche banlieue ; aucun Berrichon n'a trouvé place dans ce partage de 1900. On est loin de la situation décrite à propos du chemin de fer de Saint-Romain-de-Colbosc. En 1901, quelques actions seront mises à la disposition des Berrichons chez les notaires et dans les banques du département.

La CTI installe sa direction opérationnelle, son bureau d'études et, pour peu de temps, même son siège social à Châteauroux, bientôt transféré 49, rue Caumartin, à Paris ; deux ans plus tard, en 1907, un nouveau déménagement la conduit au 13 de la rue Auber où d'autres compagnies ont déjà leur siège ; parallèlement le capital passe à $1250000 \mathrm{~F}$. Ces changements correspondent visiblement à l'entrée dans le groupe Tartary (tabl. 13) qui inclut en 1912: le Chemin de fer de l'Est de Lyon, les Tramways départementaux des Deux-Sèvres, les Chemins de fer départementaux de l'Aube, du sud de l'Aisne et les lignes de Lunéville à Blamont, Badonviller et embranchements. 
Tableau 13. Évolution de la composition des groupes Verney et Tartary

\begin{tabular}{|c|c|c|c|c|c|}
\hline \multicolumn{3}{|c|}{ Groupe Verney } & \multicolumn{3}{|c|}{ Groupe Tartary } \\
\hline & $1912(a)$ & $\begin{array}{c}\text { Autre } \\
\text { année (b) }\end{array}$ & & $1912(\mathrm{a})$ & $\begin{array}{c}\text { Autre } \\
\text { année (b) }\end{array}$ \\
\hline Finistère & $x$ & & Est-Lyon & $x$ & \\
\hline Mayenne & $x$ & & Deux-Sèvres & $x$ & \\
\hline Côtes-du-Nord & $x$ & & Indre & $x$ & (c) \\
\hline $\begin{array}{l}\text { Tramw ays de la } \\
\text { Vienne }\end{array}$ & $\mathrm{X}$ & & Aube & $x$ & \\
\hline $\begin{array}{l}\text { Transports } \\
\text { normands }\end{array}$ & $x$ & & Aisne & $x$ & \\
\hline Eure-et-Loir & & $x$ & Loiret & & $x$ \\
\hline Ardennes & & $x$ & $\begin{array}{l}\text { Lunéville à } \\
\text { Blamont }\end{array}$ & & \\
\hline Territoire de Belfort & & $x$ & $\begin{array}{l}\text { Badonviller } \\
\text { et } \\
\text { extensions }\end{array}$ & $x$ & \\
\hline \multicolumn{6}{|c|}{$\begin{array}{l}\text { (a) Le signe } X \text { indique dans cette colonne qu'en 1912, le gro upe contrô lait ce réseau } \\
\text { (b) Le signe } X \text { indique dans cette colonne que, à un mo ment de son histoire, le gro upe a contrôlé } \\
\text { ce réseau, sans que la documentation ait permis de fixer une pério de } \\
\text { (c) Le réseau de l'Indre a été intégré au groupe Tartary à partir de } 1907\end{array}$} \\
\hline
\end{tabular}

\section{Données générales}

\section{- L'intervention de la politique}

Les débats ont été longs dans tous les départements, comme dans l'Indre. Ils prenaient une tournure particulière lorsqu'ils étaient dominés par des personnalités d'envergure nationale, comme le montre O. Joseph dans le Tarn. Entre 1883 et 1897, les conseillers généraux s'affrontent sur la question des priorités en matière de construction ferroviaire : un réseau à voie étroite couvrant le département, désenclavant notamment les Monts de Lacaune, ou une ligne de $15 \mathrm{~km}$ à voie normale, réunissant le centre industriel de Graulhet au réseau de la Compagnie du Midi, pour permettre le trafic sans rupture de charge avec Mazamet, centre mondial du délainage. Avec le baron Reille, conservateur, catholique, administrateur du PO, et ses opposants successifs, l'universitaire läque et républicain Compayré, puis de l'ingénieur centralien Level, directeur de la SGCFE et membre du Comité consultatif des chemins de fer, les arguments sont empruntés aux thèmes 
de la vie politique du moment : « Catholicisme, libre pensée, manuels scolaires [...] Nous voici loin de la question des VFIL. Nous sommes

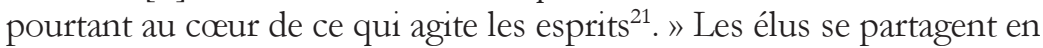
deux clans et les votes se font en fonction des convictions politiques et religieuses de chacun et non plus de l'objet central du débat, à savoir l'équipement ferroviaire du département.

\section{L'attitude des milieux financiers}

Chaque département a son histoire. Mais si ce type d'entreprise se définit clairement par son assise territoriale départementale, les projets se réalisent avec l'aide de capitaux parisiens ou lyonnais, rarement avec ceux du seul département. Des sièges sociaux isolés à Paris ou en province traduisent une indépendance que tôt ou tard l'intégration à un des nombreux groupes qui se sont formés fait disparaitre : à communauté des administrateurs, rassemblement des sièges sociaux (tabl. 14).

La situation est complexe parce que la composition des groupes évolue avec le temps, mais le mouvement de concentration dans le secteur des chemins de fer secondaires est une tendance affirmée bien avant 1914.

Entre 1840 et 1865, les milieux de la haute finance et des industries sidérurgiques et métallurgiques avaient activement soutenu la construction des principaux axes du réseau ferré : le marquis de Vogüe, Benoît d'Azy, administrateur du PLM naissant, créaient des usines pour y fabriquer des rails, des plaques tournantes, des coussinets ${ }^{22}$. Toutes les régions dotées de gisements superficiels de minerais de fer comme le Périgord et le Berry abritaient des hauts fourneaux et des forges : la concentration des industries sidérurgiques dans la Loire, le Nord, puis la Lorraine a condamné cette métallurgie dispersée. Lors de la construction des chemins de fer secondaires en revanche l'approvisionnement local en rails ou plaques tournantes est limité mais des ateliers de construction du matériel ferroviaire se sont créés. Les milieux de la haute finance fondent quelques grandes sociétés ; ils s'intéressent, à terme, à d'autres entreprises dont l'exploitation leur parait rentable, sous forme de fusion, participation ou affermage. La grande banque n'a pas été à l'origine de la multitude des entreprises qui ont assuré l'essor des réseaux secondaires, même si le groupe Empain fait exception avec ses intérêts ultérieurs en Haute-Saône et en Dordogne.

21- O. Joseph, «Le réseau des destins croisés », RHCF 24-25, p. 245-269, citation p. 255. L'auteur, on l'a dit, étudie minutieusement les implications politiques et religieuses de la question.

22- M. Wolkowitsch, L'Économie régionale des transports dans le Centre et le Centre-Ouest de la France, Paris, SEDES, 1960, 525 p., cf. p. 21-26 et 209-213. 
Tableau 14. Types de localisation de sièges sociaux et de directions opérationnelles des entreprises à assise départementales, 1912 (a)

\begin{tabular}{|c|c|c|}
\hline Compagnie & Siège social & Direction \\
\hline \multicolumn{3}{|l|}{ Siège isolé en province (b) } \\
\hline $\begin{array}{l}\text { Tramw ays départementaux de la } \\
\text { Côte-d'Or }\end{array}$ & Dijon & Dijon \\
\hline $\begin{array}{l}\text { Chemins de fer des Bouches-du- } \\
\text { Rhône }\end{array}$ & Arles & Arles \\
\hline Chemin de fer du Morbihan & Vannes & Vannes \\
\hline \multicolumn{3}{|l|}{ Siège isolé à Paris } \\
\hline Tramw ay à vapeur de l'Aude & 44 rue Blanche - Paris & Narbonne \\
\hline CFIL de l'Hérault & 95 rue Taitbout - Paris & Montpellier \\
\hline \multicolumn{3}{|c|}{ Sièges en un même lieu en province } \\
\hline Chemin de fer du Finistère & \multirow{5}{*}{$\begin{array}{l}3 \text { rue Léon-Beldant } \\
\text { Le Mans }\end{array}$} & Brest - Quimper \\
\hline Chemin de fer des Côtes-du-Nord & & Saint-Brieuc \\
\hline Chemin de fer de la Mayenne & & Laval \\
\hline $\begin{array}{l}\text { Compagnie des tramw ays de la } \\
\text { Vienne }\end{array}$ & & Poitiers \\
\hline $\begin{array}{l}\text { Compagnie des tramw ays } \\
\text { normands }\end{array}$ & & Avranches \\
\hline \multicolumn{3}{|l|}{ Sièges en un même lieu à Paris } \\
\hline Chemins de fer de l'Est de Lyon & \multirow{6}{*}{13 rue Auber - Paris } & Lyon \\
\hline $\begin{array}{l}\text { Tramw ays départementaux des } \\
\text { Deux-Sèvres }\end{array}$ & & Parthenay \\
\hline Tramw ays de l'Indre & & Châteauroux \\
\hline $\begin{array}{l}\text { Chemins de fer départementaux de } \\
\text { l'Aube }\end{array}$ & & Les Riceys \\
\hline Chemins de fer du sud de l'Aisne & & Château-Thierry \\
\hline $\begin{array}{l}\text { Lignes de Lunéville à Blamont, } \\
\text { Badonviller et embranchements }\end{array}$ & & Lunéville \\
\hline \multicolumn{3}{|c|}{$\begin{array}{l}\text { (a) Des évolutions se sont produites so it par prise de contrôle de nouvelles compagnies, so it } \\
\text { par rachat, mise sous séquestre... } \\
\text { (b) Bordeaux, Greno ble et Saint-Quentin ont également abrité des sièges, }\end{array}$} \\
\hline
\end{tabular}




\section{Le capital engagé}

La réussite de ces entreprises liées à un département exige la mobilisation d'un capital, qui oblige presque toujours à un appel au marché financier parisien. Cela se traduit le plus souvent dans les lieux de résidence des administrateurs et dans la présence parmi eux de personnalités ayant largement contribué au développement des réseaux secondaires : Tartary pour la Compagnie des chemins de fer de l'Est de Lyon, E. et F. Empain pour la Société des chemins de fer du Périgord. Cependant la première société a son siège social à Lyon, mais son siège administratif à Paris, la seconde son siège social à Périgueux, mais sa direction et ses services techniques à Paris.

Le capital engagé est infiniment plus élevé que dans le cas des entreprises plus modestes. Le prix d'émission des actions peut atteindre $1000 \mathrm{~F}$, ce qui est un mode de sélection des actionnaires (tabl. 15). Deux politiques différentes sont conduites envers l'actionnariat, l'une plus ouverte aux petits porteurs, l'autre tournée vers les milieux financiers; nous voyons, sans surprise, cette dernière appliquée par la compagnie dominée par la famille Empain.

Tableau 15. Entreprises départementales, capital engagé, résidence des administrateurs

\begin{tabular}{|c|c|c|c|c|c|}
\hline Compagnie & $\begin{array}{l}\text { Année de } \\
\text { fondation }\end{array}$ & $\begin{array}{l}\text { Capital } \\
\text { engagé }\end{array}$ & $\begin{array}{l}\text { Nombre } \\
\text { d'actions }\end{array}$ & $\begin{array}{c}\text { Prix } \\
\text { d'émission }\end{array}$ & $\begin{array}{l}\text { Résidence des } \\
\text { administrateurs }\end{array}$ \\
\hline $\begin{array}{l}\text { Nice et } \\
\text { Littoral }\end{array}$ & 1895 & 15000000 & 30000 & 500 & 5 - Paris \\
\hline Est Lyon & 1878 & 8900000 & 17500 & 500 & $\begin{array}{c}7 \text { - Paris } \\
1 \text { - Asnières }\end{array}$ \\
\hline $\begin{array}{l}\text { Pau à } \\
\text { Oloron- } \\
\text { Mauléon }\end{array}$ & 1887 & 3500000 & 35000 & 100 & 4 - Paris \\
\hline Périgord & 1887 & 3000000 & 3000 & 1000 & 4 - Paris \\
\hline $\begin{array}{l}\text { Tramw ays } \\
\text { de la } \\
\text { Sarthe }\end{array}$ & 1883 & 1400000 & 2800 & 500 & $\begin{array}{c}1 \text { - Paris } \\
2 \text { - Le Mans } \\
2 \text { - Port-Brillet } \\
1 \text { - Voutré (a) }\end{array}$ \\
\hline
\end{tabular}

(a) Ces dernières localités dans la Mayenne. 


\section{Matériel et personnel}

Ces entreprises adoptent aussi bien le statut de CFIL que de TVM. La voie étroite domine, mais certaines lignes sont à l'écartement de 1,44 m. Les bâtiments font l'objet de plus de soins que ceux des petites compagnies; beaucoup n'ont rien à envier à ceux qui équipent les gares et stations le long des lignes du plan Freycinet. Les investissements en matériel sont importants. Le parc de locomotives varie de 20 à 40 unités, plus de 35 pour les réseaux de plus de $300 \mathrm{~km}$. Le parc de voitures est différencié. Les voitures à classe unique sont très rares. Des voitures de $1^{\text {re }}$ classe circulent sur de nombreuses lignes de CFIL, en moins grand nombre sur celles de TVM. L'effectif des voitures de $2^{\mathrm{e}}$ classe l'emporte de beaucoup sur celui des voitures mixtes, caractéristiques des petites entreprises : ces dernières ne représentent qu'environ $30 \%$ du parc, plus nombreuses sur les réseaux de TVM que de CFIL. Les fourgons à l'état de deux unités dans la majeure partie des entreprises de moins de $100 \mathrm{~km}$ sont pour les autres beaucoup plus nombreux, plus de 20 en général. Les distances plus longues ont conduit les entreprises à diversifier l'offre par un confort adapté aux goûts d'une clientèle variée, quitte à faire circuler des convois plus lourds. Le parc de wagons est étoffé, rarement moins de 200, ni plus de 400, avec des matériels adaptés à la diversité du trafic. Dans l'ensemble une certaine corrélation existe entre le kilométrage exploité et l'importance du parc de matériel ; CFIL et TVM ne semblent pas avoir des politiques très différentes en matière d'investissements dans ce domaine. Certains départements, comme l'Ille-et-Vilaine, se sont dotés d'un parc qu'a priori la longueur de leur réseau ne justifie pas, sauf à y constater un trafic exceptionnellement développé (tabl. 16).

L'examen des tableaux des personnels montre que, sauf pour la division Voie et Bâtiments pour laquelle certaines compagnies se passent, on l'a dit, de responsables compétents, toutes les autres fonctions à tous les niveaux de la hiérarchie sont pourvues ${ }^{23}$. Les effectifs augmentent logiquement avec le kilométrage exploité, avec des exceptions dans les cas de TVM. Le CFIL des Bouches-du-Rhône utilise un personnel nombreux, celui de l'Hérault un nombre limité d'agents eu égard à la longueur de leur réseau. Le nombre de cadres supérieurs de l'administration centrale ne dépend pas de la longueur du réseau. L'organisation administrative est rigoureuse avec des directions opérationnelles éventuellement indépendantes du siège social : le chemin de fer de Pau à Oloron-Mauléon dont le siège est à Paris a trois directions, une par réseau, à Pau, à Oloron et à Bayonne.

23- Cf. ci-dessous chapitre viII. 


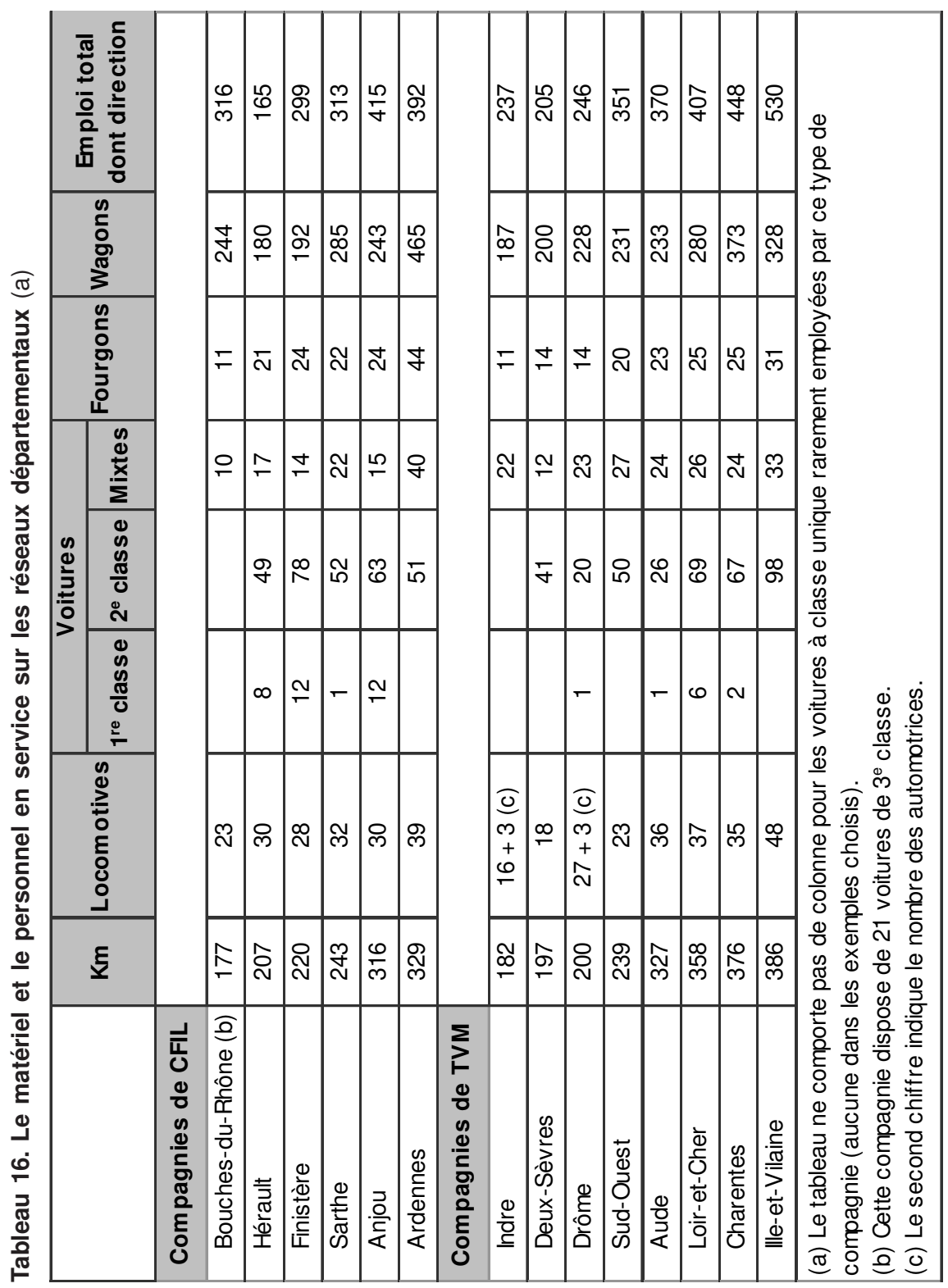




\section{$>$ Les hommes qui ont contribué à la naissance des petites entreprises et des entreprises à assise départementale}

Quels sont les hommes qui ont permis la promotion de ces réseaux? Les analyses consacrées au Chemin de fer de Saint-Romainde-Colbosc et à la Compagnie des tramways de l'Indre apportent des réponses partielles; il est nécessaire d'en faire la synthèse ${ }^{24}$.

\section{Propriétaires, négociants, entrepreneurs, ingénieurs}

Les rentiers, les propriétaires, les notaires, les représentants des banques locales sont souvent sollicités pour apporter leur soutien financier aux compagnies. Deux professions jouent un grand rôle : les entrepreneurs de travaux publics et les fabricants de matériel ferroviaire; ils apportent des connaissances techniques, ce qui n'exclut pas une participation financière. Parmi les actionnaires, on trouve un industriel marseillais qui fabrique des chaudières à vapeur, éventuellement pour équiper des locomotives. Un ingénieur montpellierain dirige la Société des ponts et travaux en fer dont l'usine a fourni des ouvrages d'art. Les carrossiers équipent les châssis reçus d'autres ateliers : voitures, automotrices, wagons passent dans leurs mains ; certains ont créé des entreprises d'une remarquable longévité : Carrel et Fouché, entreprise née au Mans à la fin du XIX ${ }^{\mathrm{e}}$ siècle, réalise la carrosserie des rames achetées par les régions dans la décennie 1980-1990. Des projets ou des regroupements de réseaux sont mis au point par des ingénieurs civils comme Tartary ou Crochat. Ce dernier, associé à Decauville, participe à des études techniques pour la mise au point d'inventions intéressant les chemins de fer. Ces entreprises se disputent les ingénieurs inventifs, tel Collardeau quittant Decauville et Crochat pour Brissonneau et Lotz.

Des recherches approfondies mériteraient d'être entreprises sur ces hommes et sur ces sociétés dont les destins ont accompagné l'histoire des chemins de fer secondaires pendant des dizaines d'années. Nous évoquerons succinctement l'histoire de deux de ces familles qui ont engendré de véritables dynasties.

24- R. Guyot a déposé à l'AHICF un manuscrit où il évoque la composition des groupes de chemins de fer secondaires et a indiqué ses sources: Arthur et Duclos "Autour des chemins de fer français, présent et avenir", in Chemins de fer secondaires, 1966, 400 p., cf. p. 193-246 ; [Anon.], "Les origines des chemins de fer secondaires », Chemins de fer régionaux et urbains, $\mathrm{n}^{\circ}$ 100, 1970-IV; Domengie, Les Petits Trains, tome I, Concessionnaires et exploitants. 


\section{Le groupe Faugère}

Faugère et Catelin tentent en vain d'obtenir la concession du réseau départemental de l'Indre, d'autant qu'ils construisent la ligne du Blanc à Argent. À la fin des travaux, ils créent une société pour exploiter la ligne; ils en sont les principaux actionnaires : Albert Andiveau, le gendre de Catelin, en est le directeur général de 1902 à 1940 ; son fils lui succèdera et « règnera » de 1940 à 1976, date de la fusion avec la CTI ; la ligne sera affermée à la SNCF en 1984. Le groupe Faugère avait exploité un temps les Chemins de fer de l'Anjou et la ligne de Bordeaux à Cadillac et partagé des intérêts dans d'autres compagnies.

\section{De l'entreprise familiale au groupe Verney (tabl. 13)}

Verney est d'abord un industriel, fabricant de matériel roulant; une partie de sa production est confiée aux ateliers de Delaroche et Turquet au Mans ; le groupe Verney rachète les ateliers et, entre 1920 et 1929, les convertit pour y fabriquer des autorails; ils sont vendus à la Société centrale de chemin de fer et d'entreprises, qui exploite des réseaux dans l'Est, et la production continue jusqu'en 1940.

Verney est aussi un constructeur et un exploitant de réseaux. En 1912, le groupe compte cinq sociétés dont les sièges sociaux sont rassemblés 3, rue Léon-Beldant, au Mans. À certaines périodes, d'autres réseaux participaient au groupe (Ardennes, Eure-et-Loir, Territoire de Belfort). Le Morbihan et l'Ille-et-Vilaine manquent à Verney pour contrôler l'ensemble du réseau secondaire de Bretagne; l'absence de la Sarthe, où est cependant le siège du groupe, l'empêche de disposer d'un réseau allant du Finistère aux limites du Loir-et-Cher. Ses ambitions se heurtaient à celles d'autres groupes : Jeancard ${ }^{25}$ pour le Morbihan, Carrel et Fouché pour l'Ille-et-Vilaine et la Sarthe enserrant « l'enclave Verney » de la Mayenne ; ce dernier exploitait aussi le réseau du Loir-etCher. Cette situation souligne comment l'octroi des concessions à l'échelle départementale a entrainé des effets contradictoires : positifs en établissant une saine concurrence entre les soumissionnaires aux appels d'offres, négatifs en limitant le nombre de réseaux voisins au sein d'un groupe, condition d'une exploitation plus économique fondée sur une utilisation rationnelle des moyens. La crainte de voir naitre des concurrences aux grandes compagnies n'avait pas cessé de hanter les esprits. Cependant, lors du développement du transport routier, les grandes entreprises ont créé de vastes réseaux en s'entendant sur des partages territoriaux ${ }^{26}$.

25- Le groupe a des intérêts dans les Chemins de fer économiques des Charentes, du Sud-Est et des projets dans le Cher.

26- M. Wolkowitsch, ouvr. cité, p. 376-381. 
Verney a su convertir progressivement ses services ferroviaires en services routiers. Le groupe a créé un département de logistique, des agences de voyages, a multiplié les réseaux de transport de voyageurs. L'acquisition récente des transports Verney par Connex, division transport de Veolia-Environnement, permet de mesurer le poids du groupe en $2002: 3500$ emplois, 2500 autocars, des réseaux urbains, périurbains et interurbains dans plus de 30 départements, un chiffre d'affaires de 198 millions d'euros. Cette entreprise familiale à l'origine née du développement des chemins de fer secondaires a traversé le siècle avec une remarquable faculté d'adaptation. Elle est devenue une très grande entreprise de transport routier au point de retenir l'intérêt d'un des premiers groupes français. Aucun autre exploitant de chemins de fer secondaires n'a connu pareille réussite.

Au-delà de la réussite personnelle, l'évolution du groupe Verney traduit une capacité à élaborer une vision de l'avenir de l'entreprise sur deux plans : sur le plan de l'innovation une faculté d'adaptation aux techniques nouvelles, autorails, autocars, puis camions ; sur celui de la stratégie, une capacité à la diversification des activités tout en restant dans le domaine des transports. Telles étaient les perspectives au cours des années 1930 ; encore fallait-il saisir les chances offertes. Les grandes entreprises, notamment la SGCFE, étaient confrontées aux mêmes choix entre les mêmes options. Les problèmes y atteignaient une particulière ampleur parce que les solutions et les décisions devaient prendre en compte la nécessité de trouver les moyens financiers nécessaires à leur application, tout en ménageant les intérêts en jeu.

\section{$>$ Les grandes entreprises}

\section{Données générales}

Trois grandes entreprises seulement opèrent dans le secteur des chemins de fer secondaires : toutes trois naissent après la loi de 1880. Deux d'entre elles constituent chacune une unité centralisée ; leur objectif est la construction et l'exploitation de lignes de chemin de fer, leur champ d'application la France ; la SGCFE y ajoute l'Algérie et les diverses colonies; en 1884, cette dernière formule est abandonnée. La troisième est un rassemblement d'entreprises conservant une relative indépendance, ses objectifs ne se limitent pas aux chemins de fer, mais visent à la diversité, son territoire n'est pas au départ défini.

Les trois entreprises ont en commun de mobiliser dès leur naissance un volume de capitaux infiniment supérieur à celui mis en œuvre par les sociétés de rang inférieur. L'appel aux grandes banques se traduit dans la composition des conseils d'administration. La puissance 
financière leur permet, à l'égal des grands réseaux, d'entretenir des relations avec les milieux politiques : elle favorise les contacts avec les élus départementaux à qui revient de régler le problème des concessions et avec les parlementaires susceptibles de faire adopter des dispositions législatives ou réglementaires favorables au dégagement de profits ${ }^{27}$. Il faut sans doute nuancer l'influence des grandes entreprises dans ce domaine : les aides publiques sont intervenues bien avant leur naissance, en Alsace, puis en Haute-Saône ${ }^{28}$. Plus tard, le principe d'un effort financier égal de l'État et des collectivités territoriales s'est généralisé. L'action des grandes entreprises a permis d'institutionnaliser les aides et les avantages financiers dont ont bénéficié toutes les compagnies engagées dans la construction des chemins de fer secondaires; à ce titre ces mesures ont favorisé le développement de tous les réseaux.

Les élus départementaux, échaudés par les déboires subis avec des concessionnaires peu compétents, parfois indélicats, sont favorablement impressionnés par le personnel de sociétés capables de fournir des projets précis et, qui plus est, d'en exécuter rapidement une partie comme le prouvent les délais parfois très brefs entre l'octroi de la concession et les premières mises en service.

Contrairement aux entreprises départementales dont nous avons noté les regroupements progressifs à l'initiative de quelques entrepreneurs comme Jeancard, Laborie et quelques autres, les grandes entreprises se proposent d'établir un vaste ensemble en multipliant les réseaux départementaux ; les procédures d'attribution des concessions, donnant la décision aux départements, ont quelque peu contrarié cette politique. Ces grandes entreprises ont exploité des lignes sous des statuts divers ; elles ont assuré la continuité du service sur des lignes ou réseaux dont les compagnies concessionnaires n'étaient plus en mesure d'exercer la responsabilité.

Les capitaux belges sont présents dans deux des grandes entreprises. La Belgique était favorable à l'établissement d'un réseau ferré de chemins de fer sur route, les chemins de fer vicinaux, pour répondre aux besoins des fortes densités de population d'une grande partie du pays ; la France est apparue, avec son étendue, un champ d'expansion possible pour des entrepreneurs qui ne trouvaient plus dans leur propre pays le moyen d'étendre leurs activités.

27- G. Ribeill, «Les chemins de fer d'intérêt local à l'épreuve du régime de 1880 : de graves pathologies congénitales?», RHCF 24-25, p. 104-137.

28- Entre Gray et Gy, en 1874, le département avait assumé $15 \%$ des dépenses, les communes $12 \%$, l'entreprise $23 \%$. 


\section{Le groupe Empain}

Nous avons relaté les débuts français du groupe Empain avec la création de la Compagnie des CFV en Haute-Saône, suivie de celle des Chemins de fer économiques du Nord. Le groupe fonde ensuite la Société des chemins de fer du Périgord qui a l'apparence des entreprises à assise départementale ; la réalité est autre : son conseil d'administration de quatre membres est dominé par Édouard et François Empain, qui entreprennent une action qui n'aura qu'une réussite partielle. La Société des chemins de fer du Périgord demande la concession d'un réseau de TVM de $154 \mathrm{~km}$; la DUP est arrêtée en 1886, la société est fondée en 1887 au capital de $3000000 \mathrm{~F}$ divisé en 3000 actions de $1000 \mathrm{~F}$; le prix de l'action très élevé garantissait une « sélection » des actionnaires parmi les milieux financiers. L'ouverture des lignes eut lieu entre 1889 et 1899. Les Empain souhaitent la fusion de cette société avec la Compagnie des chemins de fer économiques du Nord et la Société des chemins de fer à voie étroite du Midi : pour concrétiser l'opération, une émission de 6000 actions de la Compagnie des chemins de fer économiques du Nord est décidée avec échange, nombre pour nombre, d'actions des deux autres compagnies. Le Conseil d'État s'oppose à la fusion, estimant que la nouvelle société unique ne serait pas tenue au respect des obligations contractées préalablement dans chaque département par chacune des trois entreprises. La Société des chemins de fer du Périgord conserve son siège à Périgueux, François et Édouard Empain demeurent membres du conseil d'administration. Le Conseil d'État a arrêté l'opération financière, mais il ne peut s'opposer à la création d'une administration centrale unique commune aux trois entreprises ; les services s'installent successivement 3 , rue Pigalle, 8 , rue Auber et 50, rue de Lisbonne, trois adresses soulignant la fidélité des compagnies de chemins de fer secondaires à ce quartier proche de la gare Saint-Lazare.

L'échec de cette fusion conduit le groupe Empain à prendre le contrôle de plusieurs entreprises sans en modifier la situation juridique ni mettre en cause leur existence. En 1927, le baron François Empain et le général baron Empain siègent au conseil d'administration de la Société parisienne pour l'industrie des chemins de fer et des tramways électriques ${ }^{29}$; cette société a des intérêts dans les compagnies des CFV, des chemins de fer du Calvados, des chemins de fer économiques du Nord, des Tramways de Lille, de Paris et de la Seine, sans oublier le réseau métropolitain et des lignes en Isère et Savoie.

29- Société anonyme fondée en 1900 au capital de $25000000 \mathrm{~F}$ divisé en 100000 actions de $250 \mathrm{~F}$; en 1927, capital de $65000000 \mathrm{~F}$ divisé en 260000 actions de $250 \mathrm{~F}$. 
Ce groupe se caractérise par la possession de ses usines de fabrication de matériel ferroviaire, de sa banque, par la diversité de ses implantations, puisqu'il contrôle les tramways de Tachkent et du Caire et le Chemin de fer d'Afrique centrale, et par celle de ses objectifs à côté des chemins de fer : la construction de la ville d'Héliopolis ou la réalisation du zoo de Budapest.

Le groupe Empain, avec $1500 \mathrm{~km}$ de lignes, est bien la troisième entreprise de chemins de fer secondaires en France, même si sa structure est particulière.

\section{La Compagnie générale des chemins de fer départementaux}

La Compagnie des chemins de fer départementaux est une entreprise dont la majorité du conseil d'administration est étrangère : on compte cinq Belges et un Luxembourgeois pour trois Français, dont le président. Cette compagnie exploite, nous l'avons montré, un kilométrage très important de lignes d'intérêt général dont les résultats statistiques figurent dans les documents consacrés aux entreprises sous ce statut ; de même elle exploite des lignes qui lui ont été affermées, pour lesquelles les statistiques sont intégrées aux résultats des compagnies propriétaires. Aussi les seules données relatives aux chemins de fer secondaires donnent-elles une image très inexacte de cette entreprise. Si nous avons pu présenter une histoire de l'évolution de son réseau, nous ne sommes pas en mesure de dresser un portrait de cette entreprise et de son évolution dans le temps. Nous ne nous étendrons pas davantage sur son cas.

\section{La Société générale des chemins de fer économiques}

À la fin des années soixante-dix du XIx ${ }^{\mathrm{e}}$ siècle, la nécessité d'un maillage plus serré du réseau ferré pour répondre aux besoins du monde rural était admise. Convenait-il d'allonger les réseaux des grandes compagnies ou de développer un réseau de chemins de fer économiques? Tels étaient les termes du débat. Dans ce contexte, sept institutions financières, regroupant les plus puissantes de France, se sont réunies pour créer la Société d'études des chemins de fer économiques ; participaient à cette opération le Comptoir d'escompte, le Crédit lyonnais, le Crédit industriel et commercial, la Société des dépôts et comptes courants, la Société générale, la Société financière de Paris, la Banque de Paris et des Pays-Bas.

\section{Naissance de la société, composition du conseil d'administration}

Le procès-verbal de la deuxième assemblée générale constitutive de la Société générale des chemins de fer économiques montre la filiation entre la société d'études et la société de construction et d'exploitation. Il commence en ces termes : 
«Le jeudi 15 juillet 1880 à 2 heures de relevée, en la salle des délibérations du conseil d'administration de la Société anonyme la banque de Paris et des Pays-Bas, en son hôtel sis à Paris, rue d'Antin, numéros 3 et 5 , se sont réunis en deuxième assemblée générale constitutive des actionnaires de la Société générale des chemins de fer économiques, société anonyme en voie de formation au capital de vingt-cinq millions divisés en 5000 actions, de 5000 francs chacune, devant avoir son siège, sis à Paris, rue d'Antin, numéro $5 \ldots{ }^{30} »$

Ce procès-verbal indique le prix très élevé des actions à l'émission, même comparé à celui retenu par le groupe Empain lors de la fondation de la Société des chemins de fer du Périgord. La souscription est réservée en fait aux institutions financières ou à leurs dirigeants comme personnes privées. L’assemblée générale des actionnaires comptait 14 présents ; elle désigne pour six ans les sept premiers administrateurs et leur donne le droit de s'en adjoindre d'autres. Le procès-verbal précise la filiation entre la société d'études et la société créée et les apports de la première à la seconde. Les liens particuliers avec la Banque nationale de Paris et des Pays-Bas ressortent du choix du siège, la SGCFE n'entrant dans ses meubles au 4, rue de Londres, près de la gare Saint-Lazare et des sièges du PLM et du PO, que dix-neuf ans plus tard, mais surtout de la personnalité du premier président E. Joubert, qui est aussi vice-président de la Banque nationale de Paris et des Pays-Bas et qui cumulera ces fonctions pendant plus de dix ans.

Le relevé de la composition du conseil d'administration de dix ans en dix ans, de 1882 à 1912, conduit à certaines constatations.

La stabilité semble le premier trait à souligner : en trente ans, seulement dix-neufs administrateurs ont été associés à la vie du conseil ; la durée de leur participation a été très inégale. L'un, présent en 1882, 1892, 1902 et 1912 a siégé au moins trente ans ; cinq sont cités trois fois, ce qui suppose une présence d'au moins vingt ans. La majorité des administrateurs siégeait dans d'autres conseils d'administration ou occupait des fonctions de haute responsabilité bancaire, par exemple comme censeur ${ }^{31}$. Huit administrateurs de la société l'étaient aussi

30- Procès-verbal de la deuxième assemblée générale des actionnaires tenue à Paris le 15 juillet 1880, manuscrit, 4 p., voir annexe 3 .

31- Si les commissaires aux comptes vérifient la régularité et l'honnêteté des comptes présentés aux assemblées générales des actionnaires, les censeurs donnent leur avis sur les choix stratégiques de l'entreprise, ils jugent de la qualité de la gestion économique. Contrairement aux experts comptables, ils participent aux conseils d'administration, mais sans droit de vote; on les qualifie parfois d'administrateurs irresponsables. Ils sont généralement deux. 
d'institutions financières, dont ils étaient les représentants s'il s'agissait des institutions fondatrices de la SGCFE. Huit aussi siégeaient dans les conseils d'administration de compagnies de chemins de fer françaises ou étrangères, avec une prédilection pour l'Ouest. Deux seulement figuraient dans la liste des administrateurs d'entreprises industrielles. Un seul, nanti du seul titre d'ingénieur, n’a exercé qu'un mandat éphémère au sein du premier conseil d'administration. Soulignons la présence d'un comte et de trois barons ajoutant à leur titre de noblesse leur qualité de membre d'autres conseils d'administration. Dernière remarque, les postes de président et vice-président sont aux mains de quelques-uns qui se repassent les mandats, parfois en famille (tabl. 17).

\section{La société et les hommes politiques}

La composition de ce conseil d'administration est totalement différente de ceux des entreprises de moindre importance : aucun entrepreneur de travaux publics, aucun membre de professions diverses, aucun propriétaire ou rentier, aucun provincial, mais seulement des personnalités liées aux mondes de la finance et de la grande industrie. Il serait erroné pour autant de croire que la SGCFE a toujours imposé ses vues et ses conditions aux élus départementaux.

Lors de l'appel d'offres en vue d'obtenir la concession de la ligne de Vierzon à Neuilly-Moulin-Jamet dans le Sancerrois, la SGCFE a été candidate à l'octroi de la concession ; bien implantée dans le Cher, elle jugeait être en position favorable ; mais ses propositions trop éloignées de celles du département l’on fait écarter, au bénéfice de Jeancard dont A. Jacquot dresse un portrait peu flatteur, opposé à la souplesse dont aurait au contraire fait preuve la SGCFE dans les négociations avec les autorités.

«Jeancard. Ce dernier, impliqué dans plusieurs réseaux : économiques du Sud-Est, économiques des Charentes, intérêt local du Morbihan... possède une indéniable expérience en matière ferroviaire et une solide assise financière ; principal actionnaire dont le capital est très peu dispersé, il allie à ses connaissances un caractère très marqué et entier ainsi qu'une évidente âpreté au gain qui lui fait oublier quelque peu l'aspect social de ses activités. Méfiant, rusé et procédurier, il usera la patience des ingénieurs en chef et des préfets successifs qui auraient certainement trouvé plus de souplesse avec la SE déjà en place dans le département depuis de nombreuses années ${ }^{32}$.»

32- A. Jacquot, "Vierzon à Neuilly-Moulin-Jamet », L'Histoire complexe. Histoires intimes d'une petite ligne rurale, Breil-sur-Roya, Éditions du Cabri, 1997, 223 p., cf. p. 12. SE est l'abréviation de SGCFE. 

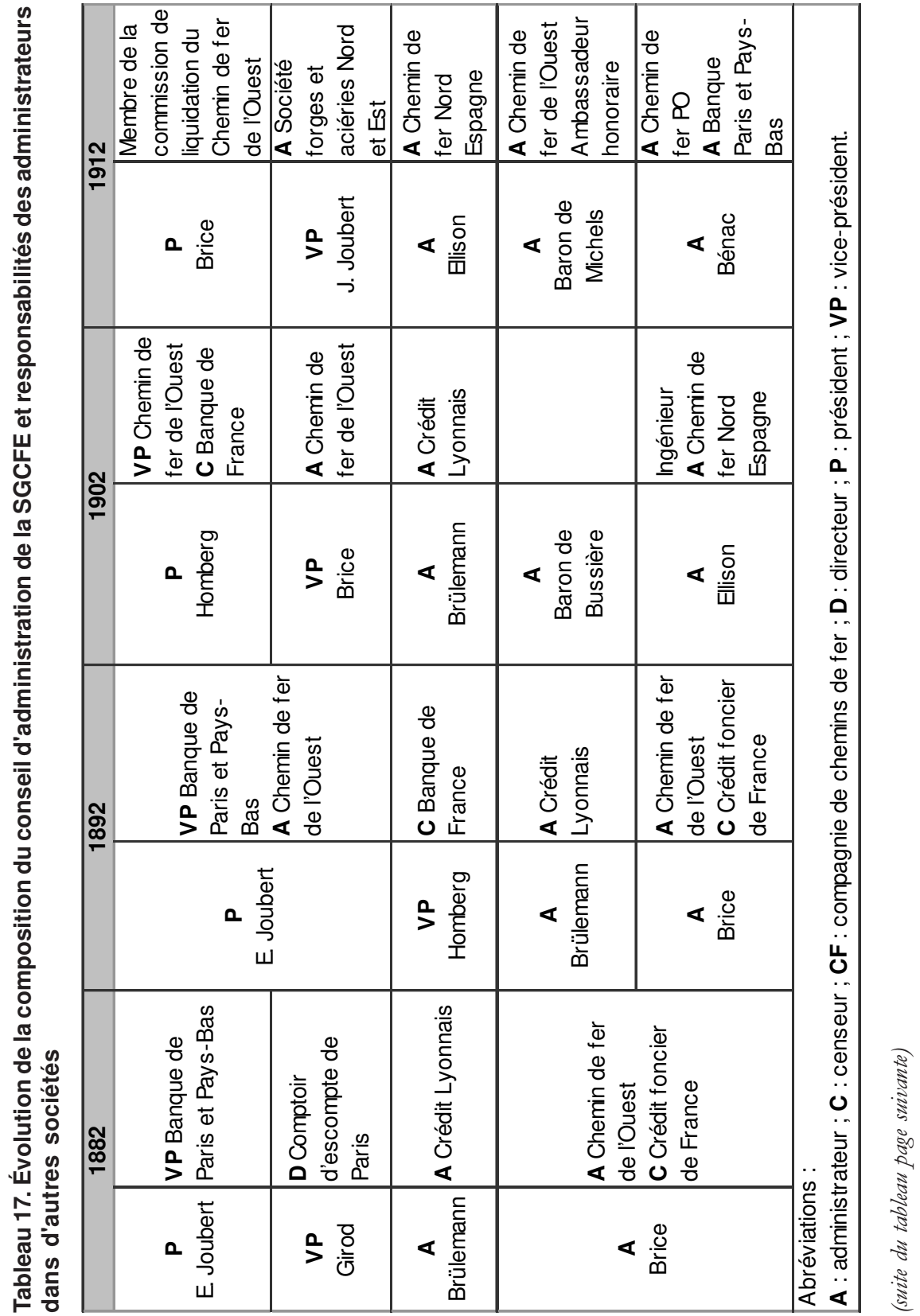


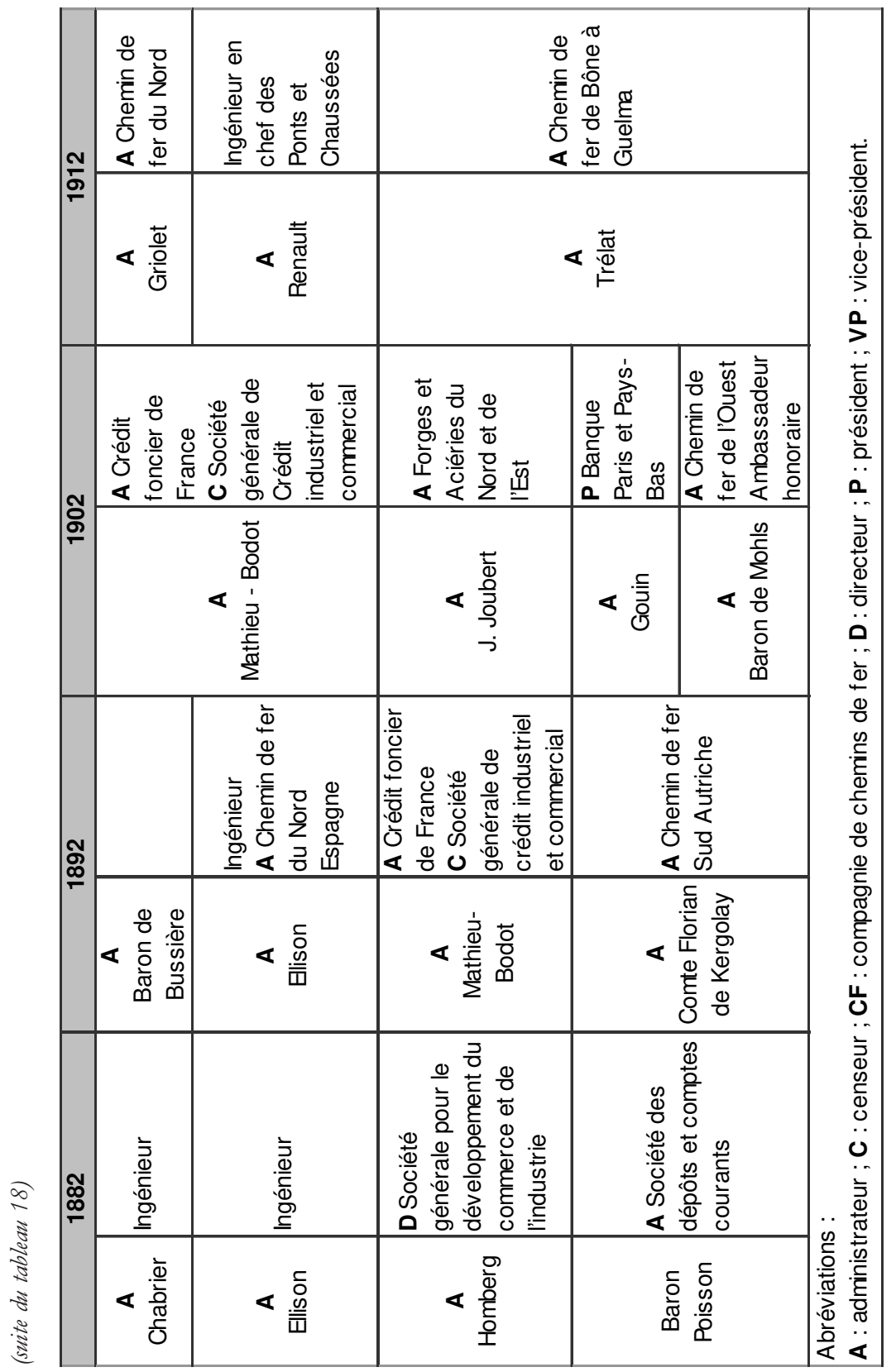


Cette souplesse de la SGCFE vis-à-vis des élus, nous en retrouvons une démonstration plus positive en Gironde. Le rapport du conseil d'administration à l'assemblée générale extraordinaire du 17 mai 1912 évoque le cas de la ligne de TVM de Bordeaux à Camarsac : «... Il ne dessert que des localités sans importance et le trafic des marchandises est presque nul. Sa longueur est de $16 \mathrm{~km}$. La dépense d'établissement entièrement à la charge de la société sans aucune subvention a été de 873 614,55 F. L'exploitation est faite aux risques et périls du concessionnaire.

Si notre société a accepté de prendre cette concession dans des conditions aussi onéreuses, c'est que le département en avait fait une condition pour nous concéder l'ensemble du réseau de la Gironde [...] La dépense faite pour la construction a été prélevée sur le capital social sans aucune émission d'obligation. » Soulignons que le département n'a eu à lancer aucun emprunt. Après sept ans d'exploitation avec de faibles bénéfices, la ligne a eu une exploitation déficitaire ${ }^{33}$.

Sans doute la puissance de la SGCFE lui permettait-elle d'influencer des élus, mais ces derniers étaient capables de refuser ses projets et de lui imposer des charges, même financières, dont elle se serait bien passée, en lui faisant espérer de nouvelles concessions.

\section{Le matériel (annexe 4)}

Le parc de matériel s'était progressivement adapté à l'évolution du réseau, et devait faire face à l'évolution des techniques. Les rapports présentés aux assemblées générales des actionnaires prennent en compte la totalité du parc, lignes concédées ou affermées, lignes d'intérêt local ou général, parc routier. Nous ne disposons pas des données relatives aux seules lignes d'intérêt local concédées ou affermées à la SGCFE que cette dernière exploite lors d'un inventaire statistique des matériels.

Les progrès techniques ont touché toutes les catégories de matériel roulant; c'est au niveau de la traction que les modifications sont les plus significatives : en 1912, la locomotive à vapeur règne sans partage ; en 1933, les automotrices et les autobus sont en service, les premières depuis plus longtemps que les seconds; d'autres types d'engins prennent de l'importance, parallèlement à la place prise par les lignes à voie normale (tabl. 18) : en 1961, on compte 80 engins de traction sur voie normale, seulement 61 sur voie étroite.

33- Cette ligne a été à terme rétrocédée à la Compagnie des tramways de Bordeaux, qui l'a électrifiée et incorporée à son réseau en 1912. 
Tableau 18. Évolution du matériel de traction de la SGCFE

\begin{tabular}{|l|c|c|c|c|c|c|c|c|}
\hline \multirow{2}{*}{} & \multicolumn{2}{|c|}{1911} & \multicolumn{2}{c|}{1931} & \multicolumn{2}{c|}{1951} & \multicolumn{2}{c|}{1961} \\
\cline { 2 - 9 } & VN & VE & VN & VE & VN & VE & VN & VE \\
\hline $\begin{array}{l}\text { Locomotives à } \\
\text { vapeur }\end{array}$ & 34 & $214(\mathrm{a})$ & 104 & 297 & 93 & 137 & 40 & 30 \\
\hline Automotrices & - & - & 18 & 23 & 28 & 37 & 23 & 26 \\
\hline $\begin{array}{l}\text { Locomotives } \\
\text { Diesel }\end{array}$ & - & - & - & - & 10 & & 16 & \\
\hline Loco-tracteurs & - & - & - & - & - & & & 5 \\
\hline Tracteurs légers & - & - & - & - & - & & 1 & \\
\hline Autobus & - & - & $6(\mathrm{~b})$ & $15(\mathrm{~b})$ & \multicolumn{2}{|c|}{78 (c) } & \multicolumn{2}{|c|}{108 (c) } \\
\hline Cam ions & - & - & - & - & \multicolumn{2}{|c|}{31 (d) } & \multicolumn{2}{c|}{82 (d) } \\
\hline
\end{tabular}

(a) Sur 214 machines, 144 appartenaient à la Société, 70 étaient affermées dont 38 circulaient sur le réseau breton.

(b) Les autobus sont dans les données de 1933 affectés à une ligne : 6 circulent le long des lignes de la Compagnie de chemin de fer de grande banlieue, parcourues aussi par 28 locomotives et 11 automotrices ; 10 desservent le réseau de l'Anjou en renfort de 26 locomotives et 7 automotrices ; 5 enfin sont affectés à l'état d'unité à diverses lignes.

(c) En 1950 et 1962, les statistiques fournissent le nombre total d'autobus en service sans autre indication.

(d) Nous ne donnons que le chiffre des camions de $5 t$ et plus. Signalons que l'examen détaillé des statistiques fait nettement apparaître une utilisation croissante des véhicules de forts tonnages, pour l'époque : 4 plus de 10 t en 1950, 33 en 1962 dont $50 \%$ dépassent 15 t.

Source : Rapports présentés aux actionnaires de la SGCFE pour les exercices considérés. Coll. A. Jacquot.

Le parc de voitures et de wagons évolue en fonction du kilométrage exploité, progressant jusque dans les années trente et déclinant au-delà (tabl. 19); il évolue aussi en fonction du trafic, la dotation en matériel affectée à une ligne à l'origine ne correspondant pas toujours à la demande. L'examen du parc propre à chaque ligne montre entre 1911 et 1931 des modifications portant souvent sur quelques unités pour les voitures, davantage pour les wagons. La diminution du parc entre 1931 et 1951 est plus sensible. Certains types de voitures circulaient seulement sur certains réseaux et relations (tabl. 20). 
Tableau 19. Évolution du nombre des voitures et wagons en service sur le réseau exploité par la SGCFE ${ }^{34}$

\begin{tabular}{|c|c|c|c|c|c|c|}
\hline \multirow{2}{*}{ Années } & \multicolumn{3}{|c|}{ voitures } & \multicolumn{3}{c|}{ wagons } \\
\cline { 2 - 7 } & VN & VE & Total & VN & VE & Total \\
\hline $\mathbf{1 9 1 1}$ & 94 & 512 & $\mathbf{6 0 6}$ & 560 & 3270 & $\mathbf{3 8 3 0}$ \\
\hline $\mathbf{1 9 3 1}$ & 264 & 771 & $\mathbf{1 0 3 5}$ & 1074 & 4660 & $\mathbf{5 7 3 4}$ \\
\hline $\mathbf{1 9 5 1}$ & 200 & 275 & $\mathbf{4 7 5}$ & 755 & 3038 & $\mathbf{3 7 9 3}$ \\
\hline $\mathbf{1 9 6 1}$ & 82 & 97 & $\mathbf{1 7 9}$ & 446 & 1222 & $\mathbf{1 6 6 8}$ \\
\hline
\end{tabular}

Tableau 20. Évolution du parc de matériel affecté à certaines lignes et réseaux de la SGCFE

\begin{tabular}{|c|c|c|c|c|c|c|c|c|}
\hline \multirow[t]{2}{*}{$\begin{array}{l}\text { Réseaux } \\
\text { ou lignes }\end{array}$} & \multirow[t]{2}{*}{$\mathrm{Km}$} & \multirow{2}{*}{$\begin{array}{c}\begin{array}{c}\text { Types de } \\
\text { voitures en } \\
\text { service }\end{array} \\
1911\end{array}$} & \multicolumn{3}{|c|}{$\begin{array}{c}\text { Nombre de } \\
\text { voitures }\end{array}$} & \multicolumn{3}{|c|}{$\begin{array}{c}\text { Nombre de } \\
\text { wagons }\end{array}$} \\
\hline & & & 1911 & 1931 & 1951 & 1911 & 1931 & 1951 \\
\hline Cher & 220 & $2^{\mathrm{e}}$ et mixte $(\mathrm{a})$ & 40 & 41 & 27 & 205 & 246 & 223 \\
\hline Allier & 285 & $2^{\mathrm{e}}$ et mixte & 54 & 62 & 16 & 537 & 583 & 348 \\
\hline Nièvre & 212 & $2^{\mathrm{e}}$ et mixte & 46 & 46 & Fermé & 214 & 285 & Fermé \\
\hline $\begin{array}{l}\text { Somme- } \\
\text { Oise }\end{array}$ & 301 & $3^{e}$ et mixte & 78 & 86 & 47 & 761 & 878 & 701 \\
\hline Gironde & 274 & $\begin{array}{l}1-2-3 \text { et mixte } \\
\text { (b) }\end{array}$ & 84 & 91 & 103 & 502 & 561 & 527 \\
\hline Nord & 112 & $3^{e}$ et mixte $(c)$ & 42 & 37 & 12 & 198 & 198 & 172 \\
\hline Breton & 427 & $3^{e}$ et mixte $(c)$ & 97 & 110 & 102 & 636 & 908 & 914 \\
\hline $\begin{array}{l}\text { Orange à } \\
\text { Buis-les- } \\
\text { Baronnies }\end{array}$ & 17 & 2-3 et mixte & 17 & 17 & 13 & 98 & 128 & 129 \\
\hline
\end{tabular}

(a) Les voitures mixtes associent la $1^{\text {re }}$ classe, soit à un fourgon, soit à la $2^{\mathrm{e}}$ classe.

(b) Hors le réseau de Gironde, des voitures de $1^{\text {re }}$ classe circulent entre Sancoins et Lapeyrouse et entre La Guerche et Châteaumeillant.

(c) Les réseaux Nord et Breton bénéficient de voitures de $3^{e}$ classe à grande capacité.

34- Voir en annexe 4 le matériel routier utilisé en 1951 
Trois types de wagons dominent pour l'acheminement des marchandises : les wagons tombereaux, qui représentent environ $40 \%$ du parc, les wagons couverts à volets mobiles, $30 \%$, les plates-formes, $20 \%$; les wagons spécialisés sont peu nombreux ; les wagons-citernes apparaissent en 1931, où on en compte trois ; cette situation ne se modifie pas. Seule novation, l'utilisation d'une centaine de wagons à bogies dans les années trente.

Deux modèles de voitures sont en service. En 1912, le partage est net entre les réseaux anciens à voie normale desservis par les voitures à deux essieux, à quelques exceptions près, et les réseaux à voie étroite parcourus par les voitures à bogies. Entre 1911 et 1931, le parc des voitures à bogies gagne 64 unités, celui des voitures à deux essieux 266 ; plus qu'à un renouvellement du parc, cela correspond aux véhicules en service sur les lignes d'entreprises dont la société avait pris le contrôle, notamment en Anjou (81 voitures), dans la Meuse (29), les Vosges (23)... Ainsi la gestion du parc de véhicules destinés aux lignes à voie étroite se complique (tabl. 21).

La société, comme toutes les entreprises de chemins de fer secondaires, recherchait des économies d'exploitation. Il fallait combiner une offre diversifiée en mettant en circulation le moins de véhicules possible ; la capacité des voitures était un élément important du choix. Les voitures à deux essieux avaient des dimensions limitant les possibilités d'aménagement intérieur : sur les rails de la société, ces voitures n'associaient pas compartiments à bagages et à voyageurs, un fourgon devait donc entrer dans la composition des trains.

Tableau 21. Capacité des voitures en service sur les réseaux de la SGCFE en 1912

\begin{tabular}{|l|c|l|c|}
\hline \multicolumn{2}{|c|}{ Voitures à deux essieux } & \multicolumn{2}{c|}{ Voitures à bogies } \\
\hline $\begin{array}{l}\text { Mixtes } 1^{\text {re }} \text { et } 2^{\mathrm{e}} \\
\text { classe }\end{array}$ & 38 places & $1^{\text {re }}-$ fourgon & 17 places \\
\hline $\begin{array}{l}\text { Mixtes } 1^{\text {re }}-2^{\mathrm{e}} \text { et } 3^{\mathrm{e}} \\
\text { classe }\end{array}$ & 38 places & $\begin{array}{l}1^{\mathrm{re}}-2^{\mathrm{e}}-3^{\mathrm{e}}- \\
\text { fourgon }\end{array}$ & 26 à 35 places \\
\hline $1^{\mathrm{re}}$ & 9 places & $1^{\mathrm{re}}-2^{\mathrm{e}}-$ fourgon & 26 à 31 places \\
\hline $2^{\mathrm{e}}$ & 40 places & $1^{\mathrm{re}}-2^{\mathrm{e}}-3^{\mathrm{e}}$ & 37 places \\
\hline $3^{\mathrm{e}}$ & 50 places & $1^{\mathrm{re}}-2^{\mathrm{e}}$ & 36 à 62 places \\
\hline \multirow{2}{*}{} & & $2^{\mathrm{e}}-3^{\mathrm{e}}$ & 46 à 56 places \\
\cline { 3 - 4 } & $2^{\mathrm{e}}$ & 38 à 64 places \\
\cline { 3 - 4 } & & $3^{\mathrm{e}}$ & 54 à 80 places \\
\hline
\end{tabular}


Après 1914, les investissements en matériel ont été consentis essentiellement pour suivre la modernisation des engins de traction; certaines acquisitions de voitures ou wagons ont été imposées pour compenser les pertes subies pendant la guerre. Mais la politique de fermeture des lignes permet des transferts de matériel vers les lignes encore en service. Parallèlement ce sont les achats d'autobus, puis de camions qui monopolisent une part croissante des investissements en matériel.

\section{Le personnel \\ $>$ Les effectifs}

Le personnel affecté à chaque ligne ou à chaque réseau dépend de la longueur à exploiter, mais, on l'a vu pour les compagnies plus petites, d'autres facteurs interviennent : le volume du trafic, la possibilité d'utiliser des agents en service sur des lignes proches exploitées par la société ; les exemples existent en Gironde et au sein du réseau Centre. La proportion entre le kilométrage desservi et l'effectif n'est pas systématique.

Retenons six réseaux et quatre lignes et classons-les par ordre décroissant de leur longueur; donnons à chacun un numéro d'ordre en fonction de leur effectif pour chaque division et pour l'effectif total d'agents en service; comparons ce classement aux effectifs en valeur absolue : ce tableau appelle les commentaires suivants (tabl. 22).

Les effectifs ne sont pas fixés en fonction de règles arrêtées puisque l'ordre n'est pas le même suivant les services. Les trois réseaux dépassant $300 \mathrm{~km}$ occupent chacun une fois la première place ; le plus long (Somme) ne regroupe pas le plus grand effectif qui se trouve dans l'Allier. Le réseau nettement le plus court est en dernière position (Seineet-Marne). La ligne de Toul à Thiaucourt, plus de deux fois plus longue que chacune des autres, est toujours en tête du classement, les trois autres occupent chacune une fois la dernière place. Les effectifs totaux de la ligne et du réseau en queue de classement sont beaucoup plus réduits que ne le supposerait leur kilométrage ; c'est à leur statut de TVM qu'ils doivent cette situation.

Les lignes ou réseaux de même longueur d'entreprises de moindre envergure ont-elles, ou non, des effectifs équivalents à leur position, ou la Société a-t-elle une situation privilégiée ? La réponse est donnée par une série de comparaisons (tabl. 23). 


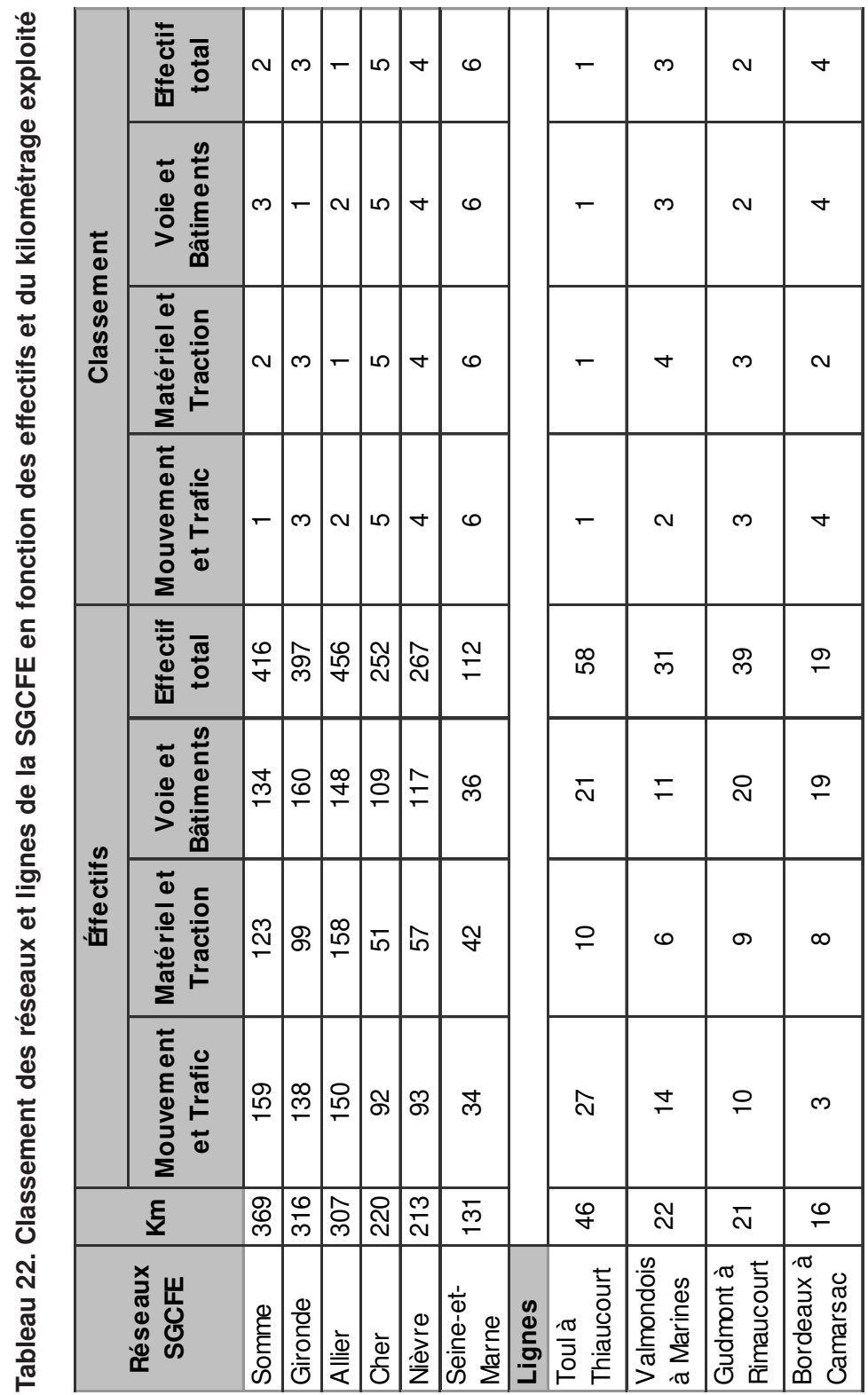




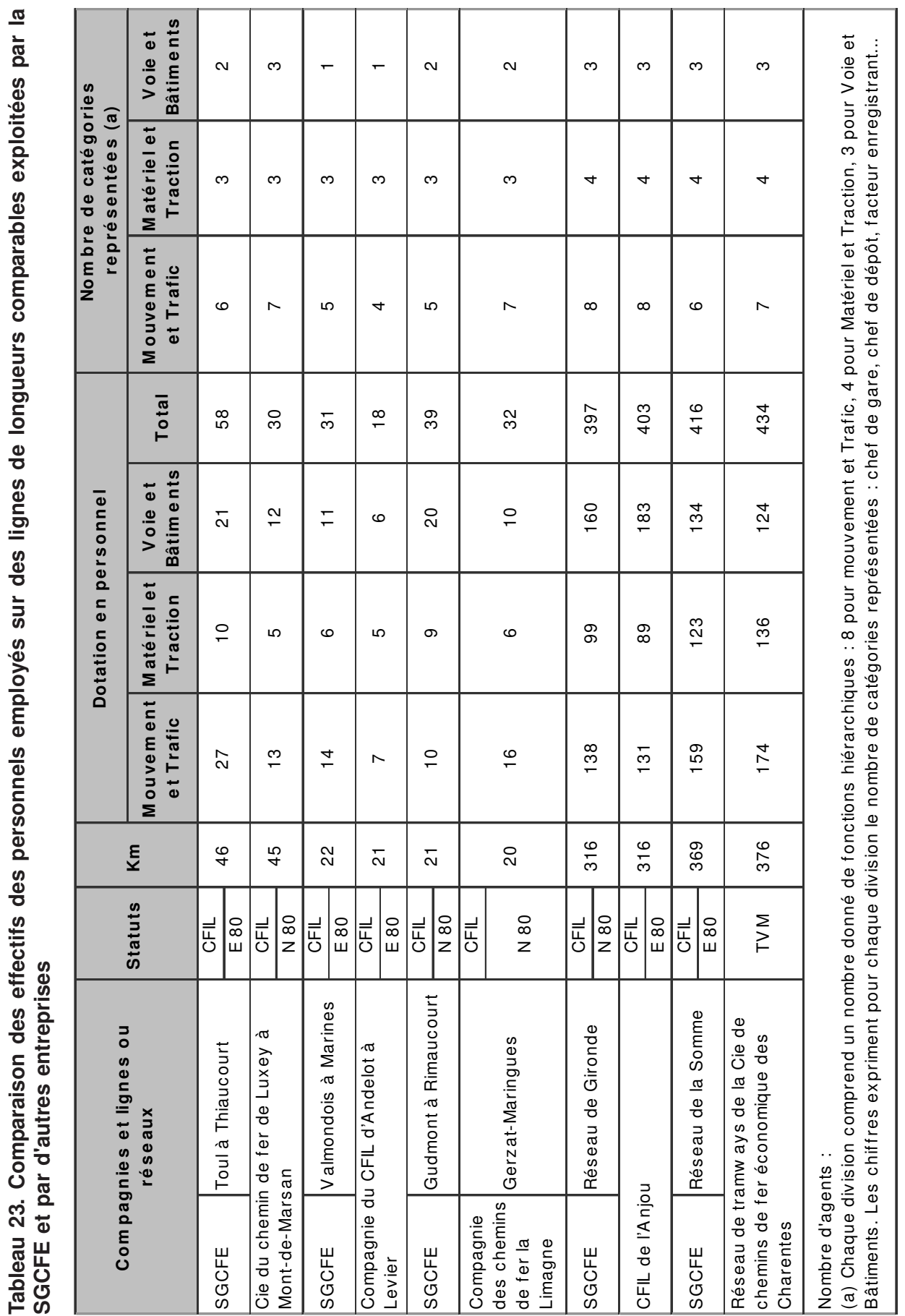


La dotation en personnel pour les réseaux est très semblable. Pour les lignes, la supériorité de la SGCFE est sensible dans tous les cas de figures et elle est double : elle s'exprime d'abord dans le nombre total d'agents, ensuite dans le degré de qualification des cadres : citons seulement le cas de la ligne de Maringues à Gerzat, exploitée par la Compagnie des chemins de fer de la Limagne qui ne compte ni ingénieur, ni architecte à la tête des divisions Matériel et Traction et Voie et Bâtiments.

\section{$>$ La politique sociale}

Les questions relatives au personnel tiennent une place limitée dans les procès-verbaux des assemblées générales des actionnaires. Certes, on y lit un hommage rituel à son attachement à l'entreprise :

«Le dévouement traditionnel de l'ensemble de nos personnels auquel chaque année nous sommes heureux de rendre hommage a permis comme par le passé d'assurer dans les meilleures conditions le service dont nous sommes chargés et d'effectuer au mieux toutes les adaptations nécessaire. » (1950).

Plus concrets sont : «les sacrifices que nous avons consentis par une série de décisions antérieures en faveur de notre petit personnel » (1912). La société avait proposé à l'homologation ministérielle en 1909 un règlement des pensions de retraite, non approuvé au terme de trois ans, dans l'attente d'une loi étendant la mesure à toutes les compagnies secondaires. Cependant la société effectuait à titre provisoire ses versements et prévenait : «Si la loi doit aggraver nos charges contractuelles, nous serons conduits à réclamer une compensation, ainsi d'ailleurs que l'ont fait les grandes compagnies dans un cas analogue.» Les autres mesures portaient sur le service médical, des achats de vêtements pour les enfants des agents et sur des secours, remplacés dans l'entre-deuxguerres par des allocations familiales ${ }^{35}$. Paternalisme pour les uns, souci de progrès social pour les autres, cette politique calquée sur celle des grandes compagnies pouvait difficilement être appliquée par la totalité des entreprises de chemins de fer secondaires ${ }^{36}$.

La SGCFE était née comme une grande entreprise ; elle a été gérée comme telle. Elle a surmonté les difficultés nées des deux guerres, ce qui n'était pas à la portée d'entreprises isolées moins puissantes, encore nombreuses dans le secteur des chemins de fer secondaires dans

35- Procès-verbaux des assemblées générales des actionnaires, 1912-1950.

36- Évolution des dépenses entre 1912 et 1932 : versements des retraites $315000 \mathrm{~F}$ et $3349000 \mathrm{~F}$, service médical 28000 et $1288000 \mathrm{~F}$, vêtements pour les enfants 41000 et $155000 \mathrm{~F}$, secours, puis allocations familiales 82900 et $404800 \mathrm{~F}$. Le lecteur ne saurait oublier la dépréciation de la monnaie en vingt ans. 
l'entre-deux-guerres. Ses dirigeants ont su et pu profiter des opportunités techniques qui s'offraient à eux et faire, à temps, de l'autocar et du camion des atouts et non des concurrents.

\section{Conclusion}

Classer les entreprises en fonction du kilométrage exploité est une opération aisée reposant sur un critère objectif indiscutable. Cela permet de constater la diversité de nature des entreprises qui participaient encore en 1911 à l'exploitation des chemins de fer secondaires.

Cette première approche, pour riche d'enseignements qu'elle soit, n'est pas pleinement satisfaisante. Une autre démarche, mariée à a précédente, s'avère nécessaire pour proposer une typologie plus fine, pour laquelle de multiples données doivent être prises en compte : les hommes, dirigeants comme exécutants, les moyens matériels, le volume des capitaux engagés...

Pour les grandes entreprises, la documentation a permis souvent de connaitre la composition du conseil d'administration, les moyens mis en œuvre, de suivre l'évolution complexe du réseau. Pour les autres, nous avons approfondi un exemple, en fonction des monographies que nous avons consultées ; puis à la lumière de la situation d'entreprises comparables, nous avons tenté de dégager les traits communs permettant de la caractériser. Cette approche nous a encore une fois convaincu de la discrétion fréquente des monographies sur la vie interne des entreprises, particulièrement sur leurs problèmes financiers. Bien que nous manquions d'analyses sur cet aspect, la nécessité de leur consacrer une réflexion particulière s'est imposée à nous. 


\section{Annexe 1}

\section{Trois exemples de lignes courtes}

(fiches signalétiques de trois entreprises extraites de l'Annuaire Marchal, en 1936, 1927 et $1911^{1}$ )

\section{RÉALMONT-LABOUTARIÉ}

\section{Cie du Tramway de Réalmont à Laboutarié.}

Société anonyme, constituée en 1902 , pour 60 ans.

Siège social et direction : Maison A. Benoit, à Réalmont (Tarn).

Dráe de la concession : 60 ans.

DOCUMENTATION OFFIC̣IELLE. - AGTES DE CONCESSION

Décret du 8 juillet 1901 (J. O. 18 juillet 1901. $-B$. des $L$. 2316). Concession.

- 17 décembre 1917. Modification des tarifs.

- $\quad 92$ juillet 1919 (J. O 99 juillet 1919). Majoration des tarifs $60 \%$

- 11 avril 1920 (J. O. 15 avril 1920). Classement tramway urbain.

- 12 mai 1928 (J. O. 19 mai 1928). Fixation du nouveau régime d'exploitation.

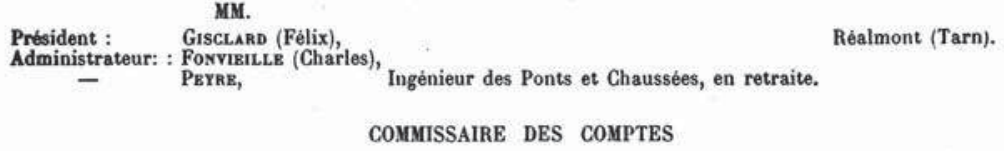

M=- Sxrrrers (Paule), née Robert, Réalmont.

\section{DIRECTION ET SERVICES TECHNIQUES}

MM. Gisclakd (Félix), Directeur, station du Tramway, Réalmont (Tarn). Taussac (Pierre), Fondé de pouvoirs.

\section{ORGANISATION FINANCIËRE}

Capital-actions : 320 actions de 250 francs entièrement libérées, soit 80.000 francs. Bilan : Les comptes ne sont pas publiès.

\section{CONTROLE ADMINISTRATIF}
MM. Aussanac, Ing. en chef des P. et Chanss, boulevard Soult, 63, Albi. Tél. : 131. Escoulè, $\quad$ Ing. des Ponts et Chaussées. Ing. des T. P. E., ch. de bureau, -
Rullakevo (Raoul), Ingénieur adjoint des T. P. E., av. du Colonel-Teyssier, 111, - DOCUMENTATION TFCHNIQUE
Longueur de la ligne: $5 \mathrm{~km}$ Largeur de la voie : $0 \mathrm{~m}$. 60 . Type de rail : Vignole $15 \mathrm{~kg}$. Déclivite maximum, $30 \mathrm{~mm}$.
Rayon minimum des courbes, $100 \mathrm{~m}$.
Gabarit du matériel. PARC DU MATÉRIEL ROULANT
Loco-tracteur. Voitures à voyageurs : 3 .




\section{$\mathrm{C}^{\mathrm{i}} \mathrm{du}$ Chemin de fer de Pont-de-la-Deule à Pont-à-Marcq.}

Société anonyme, constituée le 3 novembre 1894 , pour 85 ans.

Siège social et Direction : rue de Dunkerque, 48, Paris $\left(9^{\circ}\right)$. Tèl. : Trudaine 25-67.

\section{DOCUMENTATION OFFICIELLE}

Statuts déposès chez M- Garanger, notaire à Paris, le 27 octobre 1894

Année sociale : 1 10 janvier au 31 décembre.

Assemblée générale: Dans le courant du premier semestre.

Exploitation : Par la C* générale de voiés ferrées d'intérét local, rue de Dunkerque, 18, Paris $\left(10^{\circ}\right)$ (Directeur M. Francis Level. Tél. : Trudaine 07-20, Inter-Trudaine 94.

\section{ACTES DE CONCESSION}

Loi du 9 août 189 (J. O. 1 août 1894 - B. des L. 1671). Concession à M. A. Lambert.

Décret du 4 aout 1894 (B. dis L. 1729). Substitution de la Ci.

- 10 mai 1922 (J.O. 18 mai 1922). 23 juin 1923 (J.O. 29 juin 1923). 26 avril 1924 (J. O. 3 avril 192i). Modifications des conditions dexploitation.

- 17 février 1926 (J. O. 23 février 1926). Fixation du régime d'exploitation. Majuration dez frais de contróle.

\section{CONSEIL D'ADMINISTRATION}

4 à 7 membres, nommés pour 6 ans.

\begin{tabular}{|c|c|c|c|c|}
\hline $\begin{array}{l}\text { résident : } \\
\text { dmin.,-délègué } \\
\text { dministrateur }\end{array}$ & $\begin{array}{l}\text { Jardis (Prosper), } \\
\text { : Latrasse (André), } \\
\text { : Drquékra (Henri), }\end{array}$ & $\begin{array}{l}\text { avenue Victor-Hugo, 72, } \\
\text { av. Charles-Floquet, } 34 \text {, }\end{array}$ & $\begin{array}{l}\text { Paris }\left(16^{*}\right) . \\
\text { Paris }(\mathbf{7}) \\
\text { Pisseleux (Aisne). }\end{array}$ & $\begin{array}{l}\text { Th́l. : } \\
\text { Pany 45-73. } \\
\text { Suf 48-13. } \\
\text { Villers-Cot- } \\
\text { terets } 49 .\end{array}$ \\
\hline$\frac{-}{E}$ & 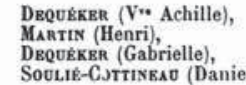 & $\begin{array}{l}\text { rue de l'Assomption, } 84 \text {, } \\
\text { place du Huit-0ctobre, 14, } \\
\text { avenue Lowendal, } 1^{\text {bix, }} \\
\text { rue de Bercy, } 50 \text {, }\end{array}$ & $\begin{array}{l}\text { Paris }\left(16^{*}\right) . \\
\text { Saint-Quentin (Aisue). } \\
\text { Paris }\left(7^{*}\right) \text {. } \\
\text { Paris }\left(\mathbf{8}^{*}\right) \text {. }\end{array}$ & $\begin{array}{c}\text { Jas } 39-5 i . \\
34-61 . \\
\text { Inval. } 00-08 . \\
\text { Êlystes } 71-18 .\end{array}$ \\
\hline
\end{tabular}

MM. VAGOGNe (Gaston),
PERNot,

\section{COMMISSAIRES DES COMPTES}

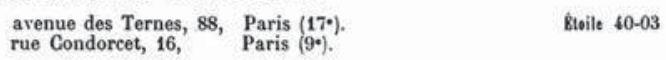

\section{SERVICES ADMINISTRATIFS}

M. Maquanxa (Louis), Chef de la Comptabilité, rue Jean-Jaurès, 52, villa Henriette, Saunois (Seine-et-0ise).

\section{ORGANISATION FINANCIÊRE}

Capital-actions : 5.800 actions de 500 fr., soit 2.900 .000 francs.

Subventions : La Cie a recu de la Cie du Chemin de fer du Nord des avances remboursables par annuités. Conditions d'exploitation. Décret du 23 juin 1923 et du 26 avril 1924 (J.O. 26 juin 1923 at 30 avril 1926 ). A dater du $1^{* r}$ janvier 1993, la Compagnie exploite a ses risques et perils suivant la convention du 19 février 1892 avec les modifications suivantes:

Les recettes provenant de ces majorations n'interviennent pas dans le terme $\mathrm{R}$ de la formule $200+$ représentant les frais d'exploitation par $\mathrm{km}$. dans la subrention d'insuffisa ce.

\section{CONTROLE ADMINISTRATIF}

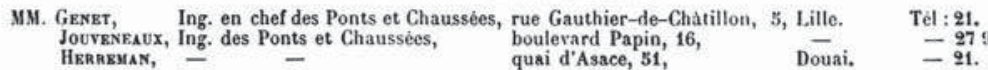

\section{DOCUMENTATION TECHNIQUE}

Longueur du réseau en reconstruction : $29 \mathrm{~km}$. | Rayon minimum des courbes $2: 0 \mathrm{~m}$.

Largeur de la voie : $1 \mathrm{~m}$. 14 .

Type de rail : Vignole $25 \mathrm{~kg}$. Gabarit du matériel roulant : $\mathbf{2} \mathrm{m} .80$.

Locomotives : 2 .
Voitures a voyageurs : 6 .

PARC DU MATÉRIEL ROULANT 


\section{Compagnie du Tramway \\ de \\ PONTARLIER à MOUTHE}

Décl. d'ut. publ. 21 juillet 1897. - Ouv. à l'expl. 1er mai 1900.

(Traclion à vapeur, locomolives. - Voie de 1 métre).

Voyageurs et marchandises (G. E.) (29 km. 585$)$.

LIGNE dE : Pontarlier à Mouthe (Doubs).

Socı̇té axoNyas, constituée le 5 septembre 1897 , pour 50 ans. Capital : 500,000 francs, divisé en 3,000 actions de 100 francs, libérées.

Stźge socıst. : Pontarlier (Doubs).

CONSEII. D'ADMINISTRATION

MM. VANDEL,

Président,

à Pontarlier.

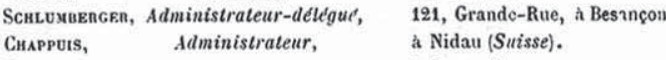

$\mathrm{N} . . ., \quad-\quad$ à Pontarlier.

LETounlox,

COMMISSAIRES DES COMPTES

MM. Mrunikr, à Pontarlier.

L.ect.enc,

DIRECTION ET SERVICES TECHNIQUES

MM. Revox, Ingénieur principal, à Morteau (Dou's). Hyexne, Chef d Exploilation, a Pontarlier.

sTATIONS.

Pontarlier,

Mercier, Chef de station.

La Cluse.

Mm. Bosilutzan, Chei de slation.

Oye et Pallet.

AT. Barthei.er, Chef de station.

Chaon.

Iite Girard, Chef de station.

Chaudron.

Mite IfsugaIx, Chef de station.

Malbuisson.

3. Dubre, Chef de slation.
Les Granges.

N. Ronne, Chef de statio.t.

Labergemont.

M. Comre, Chef de station.

Brey.

M Denizet, Chef de station.

Gellin.

M. Vioxner, Chef de station.

Sarrageois

М. Тномет, Chel de station.

Mouthe.

M. Carr, Chef de station. 


\section{Annexe 2 \\ Deux exemples de réseaux}

(fiches signalétiques d'entreprises extraites de l'Annuaire Marchal, 1927)

COMIPAGNIES SECONDAITES

\section{Compagnie des Chemins de fer l'EST}

de

LYON

(Intẻrèt local) (N. G.) (102 km.). Voie de $1 \mathrm{~m} .44$. - Industriel $(3 \mathrm{~km}$.) (Voie de $1 \mathrm{~m} .44)$. Décl. d'ut. publ. le 14 août 1877. - Ouv. à l'expl. le S1 octobre 1881.

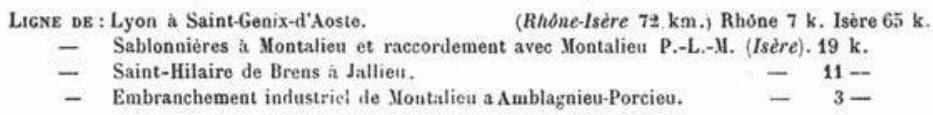

SociÉrè AxoxruE, constituée le 13 février 1878 , pour 98 ans.

Capital : 8,900,000 francs, divisé en 17,800 actions de 500 francs, dont 7,000 ordinaires et 10,800 privilégiées.

Sṫ̇Ge sociat : 54-5̌6, avenue Félix-Faure, à Lyon. Siżge adyixistratif : 13 , rue Auber, à Paris.

CONSEII, DADMINISTRATION
MiM. Galicier (Albert), Président, 81, rue Saint-Lazare, a Paris.
LÉvx (Raphä̈l-Georges), Vice-Prísident, 26, rue Victor-Hugo,
JovBent (Alfred), Administrateur-délégue, 160, boulevard Haussmann, -
VIAL (Francisque), Administrateur, 4, rue de l'Arcade,
Seviricz (Alexaudre), 二
CAHEx D'ANvers (Ch.), - $\quad$ 2, rue Bassano,
Fabre (Émile), - 3, rue Magenta,
TARtaky (Georges), _ _ 7, rue de Naples,

COMMISSAIRE DES COMPTES

$$
\text { M. X... }
$$

DIRECTION

M. Mıchel.er (R.), Directeur de l'Exploitation, 34-56, a a enue Félix-Faure, à Lyon. SERVICES DE L'EXPLOITATIOX

MM. Prisut, Ingénieur du Matériel de ia Traction. | MM. Coupois, Chee du Mouvement $\mathbb{f}^{\mathrm{m}}$. Gruizard, Ingénieur de la Voie.

$$
\text { Chounot, Chef de la Comptabilité. }
$$

GARBS ET STATIONS.

Ligne de Lyon A Aoste-Saint-Gienix.

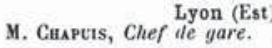

Villeurbanne.

M. Masson, Chef de gare.

$$
\text { Dècines. }
$$

M. Faxсm, Chef de gare. Meyzieu.

M. Gentix, Chef de gare.

$$
\text { Pusignan. }
$$

M. Mrulox, Chef de gare. Janneyrias.

M. Cumix, Chef de gare.

Pont de Cheruy-Tignieu.

M. Gagnirox, Chef de gare.

St-Romain-Barens.

M⿻ Brocaier, Chef de halle.

$$
\text { Crémieu. }
$$

צ. Manitaz, Chef de gare.
Dizimieu-les-Tronches.

M. Fotaxentit, Chef de gare. St-Hilaire de-Brens.

M. Ravaz, Chef de gare.

M. Defnèa, Chef de gare. Soleymieu-Sablonnières.

M. Foensien, chef de gare.

M. Simoxi, Chef de gare.

Morestel.
M. Troxet, Chet de gare.

Thuellin. Te gare. Les Avenières-Veyrins.

M. Flacmet, Chef de gare.

Aoste-Saint-Genix.

M. Discheletres, Che'f de gare. 
TRAMUVAYs

\section{Société des Chemins de fer \\ du \\ PÉRIGORD}

Décl. d'ut. publ. 31 décembre 188rî. - Ouv, à l'expl. 1888-1899.

(Traction à vapeur, locomotives. - Voie de 1 mètre).

Vuyageurs et marchandises (G. E.) ((15i km:).

LIGKE DE : Périgueux a Saint-Pardoux-la-Rivière (Dordogne), $54 \mathrm{~km}$.

- Périgueux à la Juvénie, embranchement du port de la (itè à Périgueux (Dordogne), $68 \mathrm{~km}$

- La Juvénio à Saint-Yriex, raccordement avec la station du réseau d'Orléans (Haute-Vienne), 8 k

- Périgueux à Vergt (Dordogne), $24 \mathrm{~km}$.

SoctétÉ axuxrye, constituée le 21 mai 1887, pour 99 ans.

Capital : 3,000,000 de francs, divisé en 3,000 actions de 1.000 franes, entièrement libérées. SıÉgr socıAt, : à Périgueux.

MM. Doxiol (Ang.),

CONSEIL D'ADMINISTRATION

EMpaix (Ed.)

President,

96 bis, rue de la Tour

EMPaIX (fr.),

Administrateur,

50, rue de Lisbonne,

Chanlier,

COMMISSAIRES DES COMPTES

MM. DeLhayé (Félix)

Bounson.

DIRECTION ET SERVICES TECHNIQUES

Administration centrale.

M. WAxphe (A. de), Directeur général, 123, ruo de Longchamp.

DIRECTION LOCALE

MM. Botreav, Directeur de l'Exploitation, a Pèrigueux.

Broedichox, Comptable,

Vigsol.t.e, Agent commercial, -

Massol, Chef de Dépót,

Antonne-Escoire.

Arsault (L').

Ateliers d'0riéans.

Barres (Les).

Brantôme.

Breuilh-Fraysse.

Champagnac.

Chancelade.

Charriéras.

Château-l'Évéque.

Coulaures.

Couloumeix.
sTATIONS

\begin{tabular}{l|l|l} 
Courant (Le). & N.-D. de Sanilhac. & Saint-Pantaly. \\
Dognon-Mayac. & Octroi de Toulon. & Saint-Pardoux. \\
Eglise-Neuve. & Payzac. & Saint-Vincent. \\
Excideuil. & Périgueux (Pl.Francheville) & Salines (Les). \\
Glandon. & Pont-de-la-Beauronne. & Sarliac. \\
Grises (Les). & Pont-du-Cerf. & Savignac. \\
Jalots (Lss). & Preyssac. & Séminaire (Le). \\
Juvénie (La). & Quatre-Routes-de-Bord. & Sencenac-Puy-de-Fou \\
Lanouaille. & Quinzac-Villars. & Statue-Montaigne. \\
Laurière. & Saint-Frout. & Trélissac. \\
Morance-Treillière. & Saint-Georges. & Valeuil-Bourdeille. \\
Moulin-de-Grenier. & Saint-Martial. & Vergt.
\end{tabular}

Tramway de PERPIGNAN et banlieue

Décl. d'ut. publ, 29 juillet 1903.

(Traction electrique, fl aérien. Vnie de 1 mètre).

Voyageurs, bagages et messageries $(18 \mathrm{~km}$.$) .$

Vork : Compagnie centrale de Tramways électriques. 


\section{Annexe 3}

\section{Procès verbal de l'assemblée générale des actionnaires de la SGCFE (1880)}

\section{Procès-verbal \\ de la deuxième assemblée générale des actionnaires tenue à Paris le 15 juillet 1880}

Le jeudi, 15 juillet 1880 à 2 heures de relevée, en la salle des délibérations du Conseil d'administration de la Société anonyme La Banque de Paris et des Pays-Bas, en son hôtel sis à Paris, rue d'Antin, numéros 3 et 5 ,

Se sont réunis en deuxième assemblée générale constitutive les actionnaires de la Société Générale des chemins de fer économiques, société anonyme en voie de formation au capital de vingt-cinq millions de francs, divisé en 5000 actions de 5000 francs chacune, devant avoir son siège à Paris, rue d'Antin $n^{\circ} 5$, et dont les statuts ont été établis suivant acte reçu par Maître Duglan et son collègue, notaires à Paris le 3 juillet 1880 .

L'examen de la feuille de présence déposée sur le bureau constate :

Que quatorze personnes composent l'assemblée ;

Que ces personnes, tant en leurs noms privés comme actionnaires, que comme mandataires d'autres actionnaires, représentent les 5000 actions formant la totalité du fonds social,

Et qu'elles ont droit ensemble à quatre-vingt-deux voix d'après la loi et les statuts combinés.

Après cette constatation, l'assemblée a de suite composé le bureau en nommant :

Comme Président, M. Joubert

Pour Scrutateurs, MM. Girod et Homberg

Et pour Secrétaire, M. Durrieu

Qui tous quatre ont accepté les fonctions dont ils viennent d'être investis.

M. le Président expose en peu de mots quel est l'objet de la réunion et lit l'ordre du jour.

Après cet exposé, M. le Président donne la parole à M. Fourchault, Commissaire spécial nommé par la première assemblée générale du sept juillet courant, pour lire le rapport qu'il a dressé le 
8 du dit mois de juillet et dont des exemplaires imprimés ont été, dès cette date, tenus au siège social, à la disposition de tous les actionnaires, ainsi que les divers membres de l'assemblée le reconnaissent.

M. Fourchault donne lecture de ce rapport par lequel il conclut à l'approbation des apports faits autrement qu'en numéraire et à l'allocation des attributions faites en retour de ces apports spéciaux, en même temps qu'il approuve les différents avantages conférés par les statuts à diverses personnes.

Personne n'ayant demandé la parole sur les diverses questions mises à l'ordre du jour et l'assemblée s'étant déclarée édifiée et prête à voter sur les propositions soumises à son contrôle, M. le Président a appelé l'assemblée à se prononcer successivement sur les diverses questions et celle-ci a arrêté les dispositions suivantes :

$1^{\circ}$ - Elle a approuvé les apports faits autrement qu'en numéraire par le liquidateur de l'ancienne Société d'études des chemins de fer économiques et a accepté les allocations faites par les statuts en retour de ces apports.

$2^{\circ}$ - Elle a également adopté toutes les dispositions des statuts qu'elle maintient intégralement dans leur teneur originaire.

$3^{\circ}$ - Elle a fixé les jetons de présence du Conseil d'administration à cinquante mille francs que le Conseil répartira entre les membres comme il l'entendra.

$4^{\circ}$ - Elle a accordé une rémunération annuelle de douze cents francs au Commissaire de surveillance.

$5^{\circ}$ - Elle a nommé comme membres du premier Conseil d'administration, dont les pouvoirs dureront six ans à partir du premier juillet courant.

M. Girod,

M. Mathieu-Bodet,

M. Brölemann,

M. le baron Poisson,

M. Homberg,

M. le baron de Bussière,

Et M. Joubert.

$6^{\circ}$ - Elle a conféré au Conseil ainsi composé le droit de s'adjoindre de nouveaux membres et à procéder en cas de vacance ou empêchement à la nomination de nouveaux membres jusqu'au nombre maximum fixé par les statuts, mais le tout à titre provisoire seulement et sauf à l'assemblée générale qui suivra les nominations qui pourront être ainsi faites, à ratifier ou modifier les choix du Conseil. 
$7^{\circ}$ - Elle a nommé comme Commissaire de surveillance pour le premier exercice social :

M. Charles Gustave Fourchault propriétaire demeurant à Paris, rue Louis le Grand $n^{\circ} 19$.

$8^{\circ}$ - Elle a donné acte aux diverses personnes ci-dessus nommées comme membres du Conseil d'administration ou comme Commissaire de surveillance, de la déclaration d'acceptation des dites fonctions qui vient d'être faite par sept de ces personnes qui sont présentes et par son mandataire pour M. le baron Poisson non présent en personne.

$9^{\circ}$ - Elle a déclaré que la Société générale des chemins de fer économiques était définitivement constituée, toutes les formalités préalables exigées par la loi et par les statuts ayant été régulièrement accomplies.

$10^{\circ}$ - Elle a donné tous pouvoirs au porteur d'une expédition ou d'une copie de tous actes relatifs à la constitution de la société pour en faire opérer le dépôt et la publication dans les conditions fixées par la loi.

$11^{\circ}$ - Elle a spécialement constaté :

Que toutes les résolutions ci-dessus arrêtées ont été successivement formulées dans l'ordre ci-dessus tracé.

Qu'elles ont toutes été prises à l'unanimité des voies des divers membres de l'assemblée, sauf les exceptions dont il va être parlé.

Que M. Fourchault a été nommé Commissaire par dix des quatorze personnes composant l'assemblée, mais avec la presque totalité des voix comptant au vote.

Et que les représentant des sept sociétés anonymes Le Comptoir d'escompte - Le Crédit industriel et commercial - Le Crédit Lyonnais La Société des dépôts et comptes courants - La Société générale - La Société financière de Paris - La Banque de Paris et des Pays-Bas et MM. le baron de Bussière et Joubert se sont abstenus de prendre part au vote sur la résolution relative aux apports faits autrement qu'en numéraire et aux attributions faites en retour de ces apports, attendu que ces sociétés et MM. de Bussière et Joubert étaient intéressés dans la question, en leur qualité d'actionnaires de l'ancienne Société d'études des chemins de fer économiques, dont le liquidateur a concouru aux statuts du 3 juillet 1880 pour opérer des apports spéciaux et pour stipuler en retour des attributions particulières. 
M. le Secrétaire a donné lecture à l'assemblée du procès-verbal de la séance et l'assemblée en a adopté la rédaction.

Après quoi les membres du bureau ont signé le procès-verbal, le Président a levé la séance et l'assemblée s'est retirée à trois heures du soir.

Les Scrutateurs

Le Président

Homberg Joubert

Girod

Le Secrétaire

Durieu 


\section{Annexe 4}

Effectif du parc routier de la SGCFE en 1950 et 1962

(extrait du rapport aux actionnaires pour l'exercice considéré)

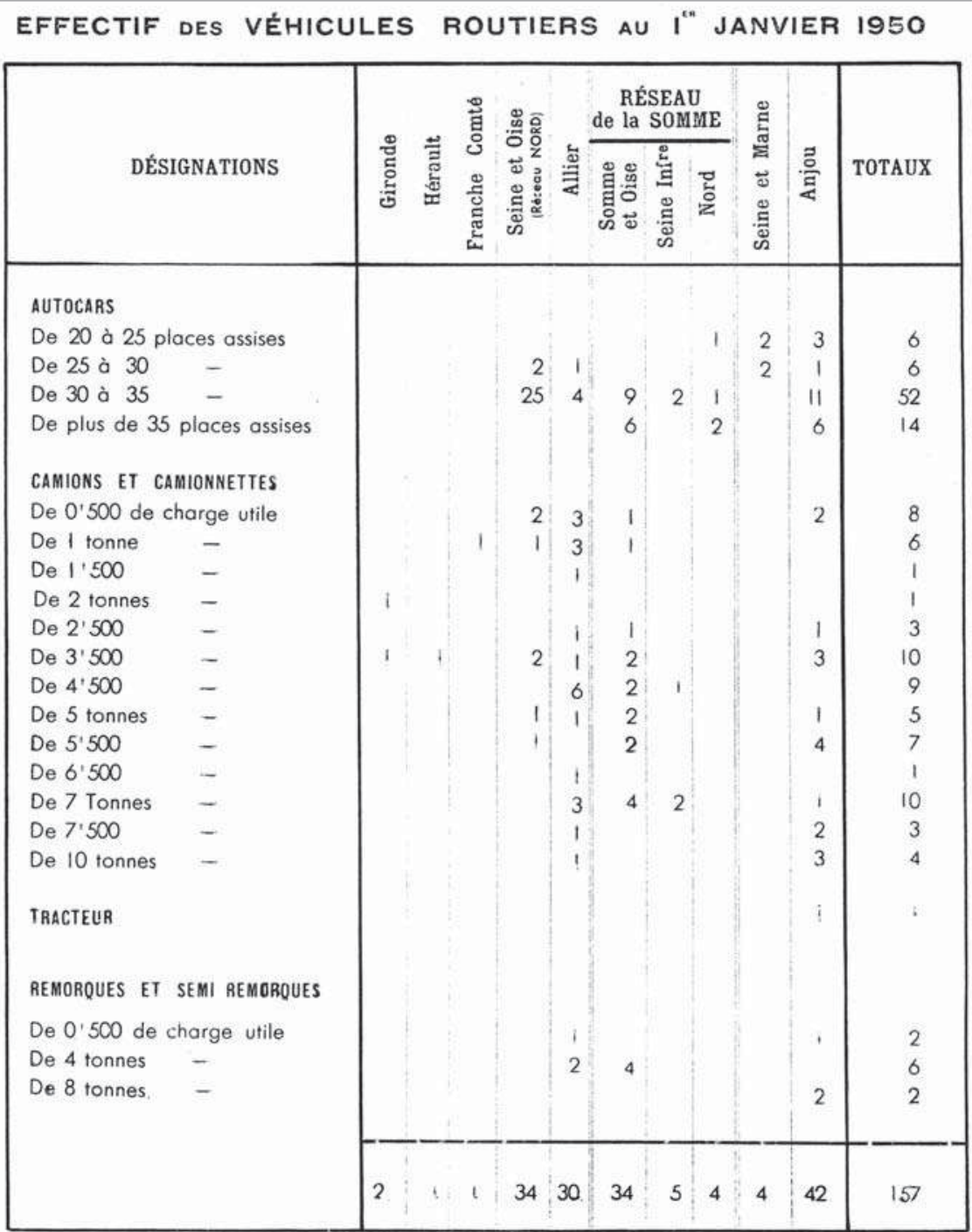


EFFECTIF DES VÉHicules ROUTIERS AU I" JANVIER 1962.

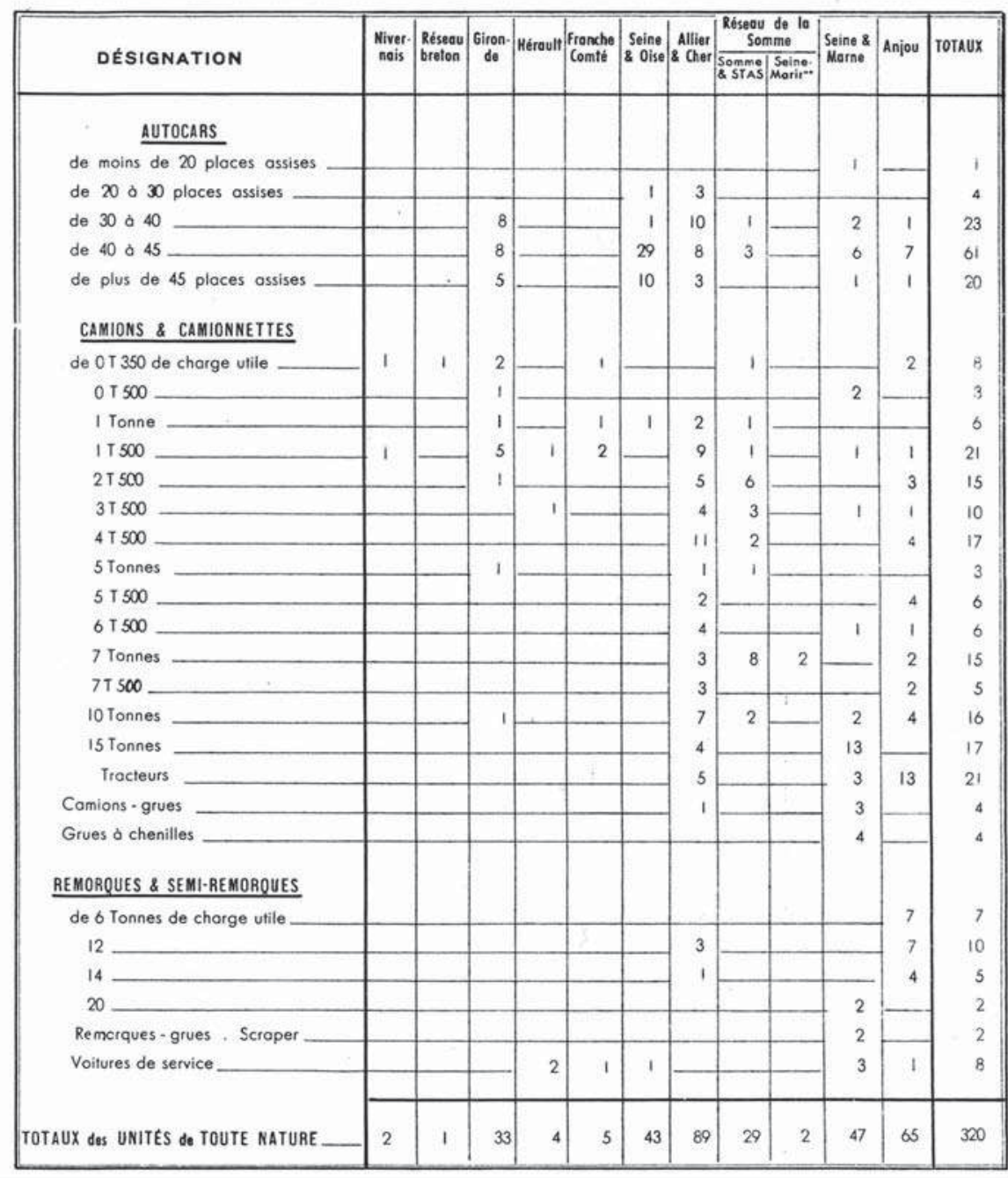

